\title{
A MULTI-OBJECTIVE APPROACH UNDER UNCERTAINTY FOR DESIGNING A GREEN MEAT SUPPLY CHAIN NETWORK
}

by Fatemeh Mohebalizadehgashti

\author{
A thesis presented to Ryerson University \\ in partial fulfillment of the \\ requirement for the degree of \\ Master of Applied Science \\ in the Program of \\ Mechanical and Industrial Engineering
}

Toronto, Ontario, Canada, 2019

(c) Fatemeh Mohebalizadehgashti, 2019 


\section{AUTHOR'S DECLARATION}

I hereby declare that I am the sole author of this thesis. This is a true copy of the thesis, including any required final reversion, as accepted by my examiners.

I authorize Ryerson University to lend this thesis to other institutions or individuals for the purpose of scholarly research.

I further authorize Ryerson University to reproduce this thesis by photocopying or by other means, in total or in part, at the request of other institutions or individuals for the purpose of scholarly research.

I understand that my thesis may be made electronically available to the public. 


\title{
ABSTRACT \\ A MULTI-OBJECTIVE APPROACH UNDER UNCERTAINTY FOR DESIGNING A GREEN MEAT SUPPLY CHAIN NETWORK
}

\author{
Master of Applied Science, 2019 \\ Fatemeh Mohebalizadehgashti \\ Mechanical and Industrial Engineering \\ Ryerson University
}

Traditional logistics management has not focused on environmental concerns when designing and optimizing food supply chain networks. However, the protection of the environment is one of the main factors that should be considered based on environmental protection regulations of countries. In this thesis, environmental concerns with a mathematical model are investigated to design and configure a multi-period, multi-product, multi-echelon green meat supply chain network. A multi-objective mixed-integer linear programming formulation is developed to optimize three objectives simultaneously: minimization of the total cost, minimization of the total $\mathrm{CO}_{2}$ emissions released from transportation, and maximization of the total capacity utilization. To demonstrate the efficiency of the proposed optimization model, a green meat supply chain network for Southern Ontario, Canada is designed. A solution approach based on augmented $\varepsilon$-constraint method is developed for solving the proposed model. As a result, a set of Pareto-optimal solutions is obtained. Finally, the impacts of uncertainty on the proposed model are investigated using several decision trees. Optimization of a food supply chain, particularly a meat supply chain, based on multiple objectives under uncertainty using decision trees is a new approach in the literature.

Keywords: Meat supply chain; Decision tree; Multi-objective programming; Mixed-integer linear programming; Augmented $\varepsilon$-constraint. 


\section{ACKNOWLEDGEMENTS}

I am deeply thankful to my supervisors, Dr. Saman Hassanzadeh Amin and Dr. Hossein Zolfagharinia, who guided me in a right direction with their comprehensive knowledge. I feel a profound gratitude for their patience, valuable guidance, motivation, and enthusiasm.

I must express my very heartfelt gratitude to my brother, Hadi, for his strong support during my master period. I would not be able to achieve my master degree without his tremendous help. Furthermore, I am grateful to my husband, Mehdi Shahini, for his emotional support, great encouragement, and enthusiasm.

My sincere thank is for my lovely parents for their endless love and support, continuous encouragement throughout my study. I could not live and study in Canada, out of my home country, without having their emotional support. 


\section{Table of Contents}

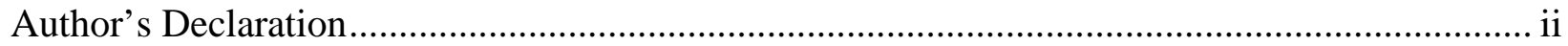

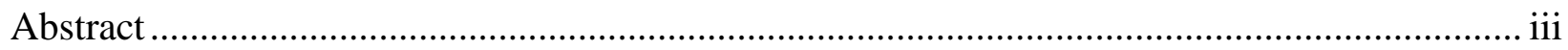

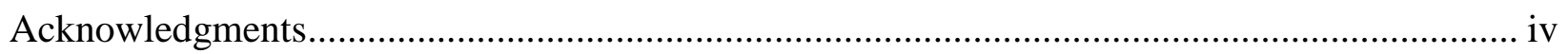

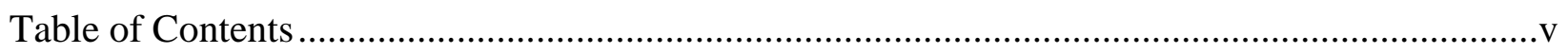

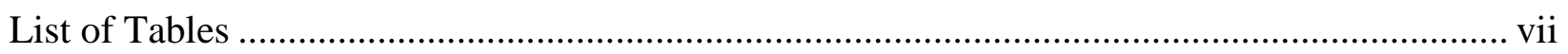

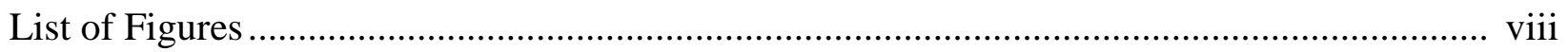

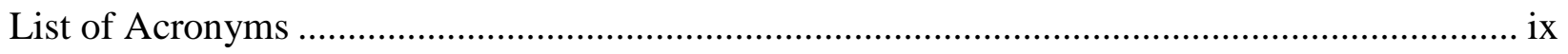

\section{CHAPTER 1: INTRODUCTION}

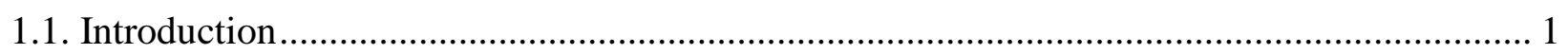

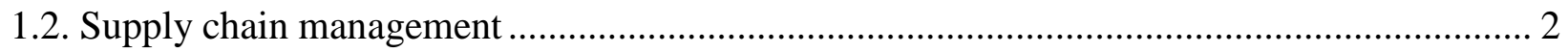

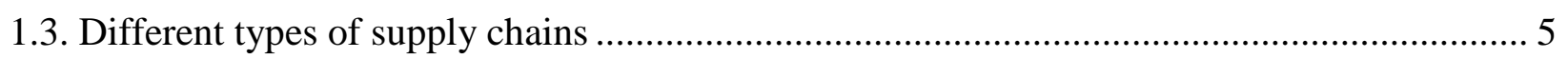

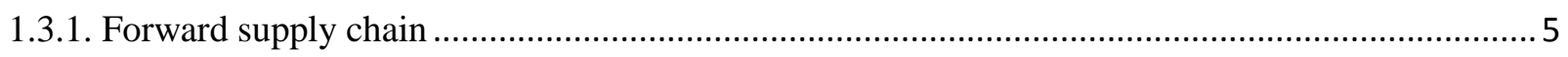

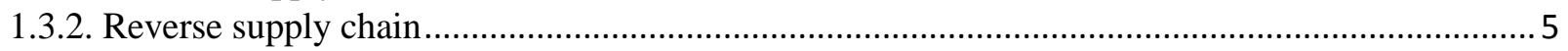

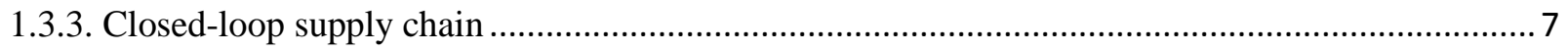

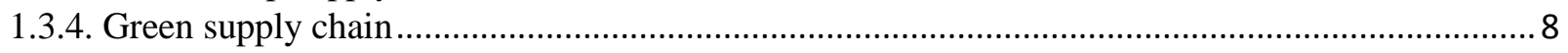

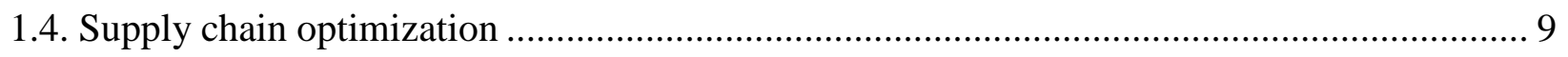

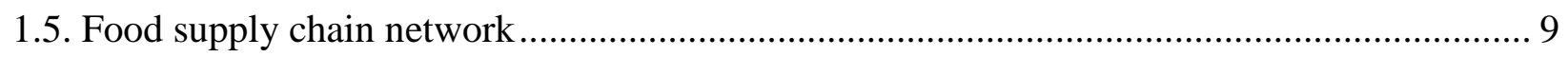

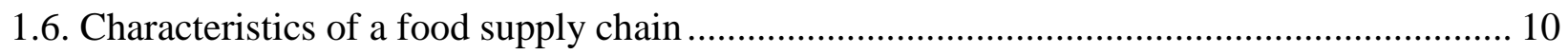

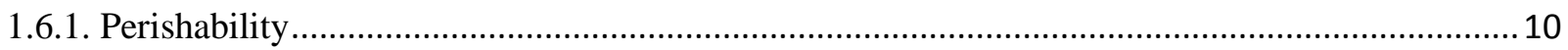

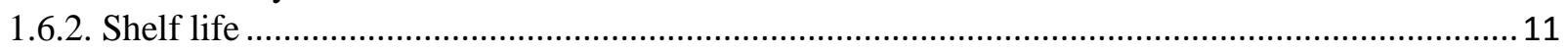

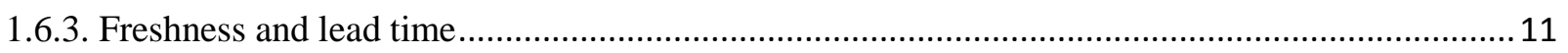

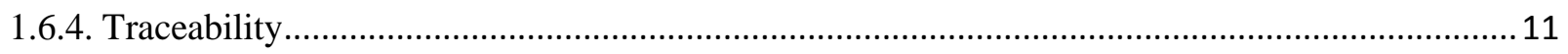

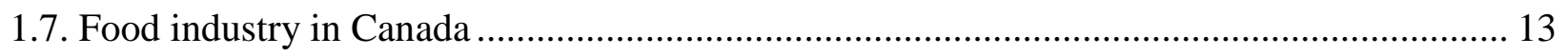

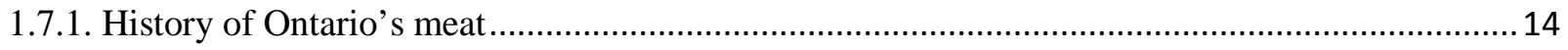

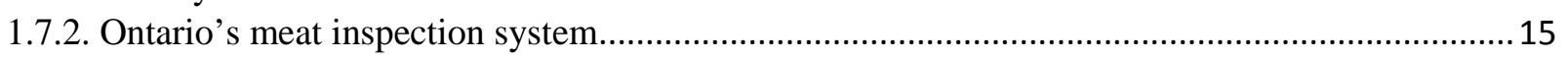

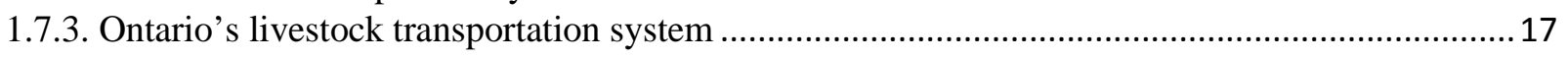

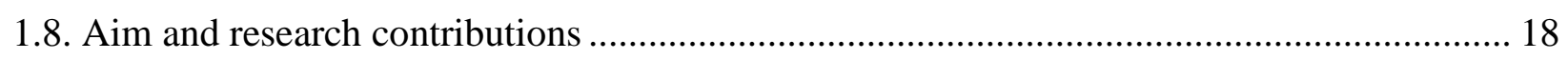

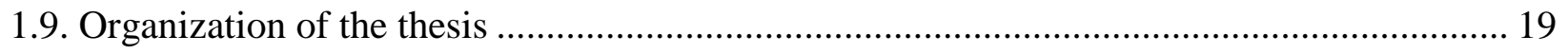

\section{CHAPTER 2. REVIEW OF LITERATURE}

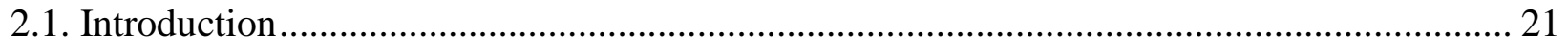

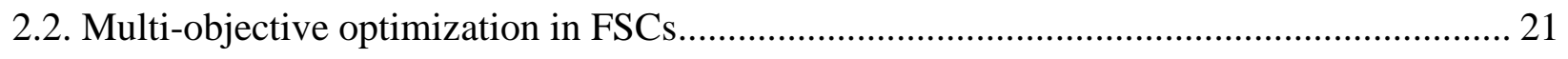

2.3. Optimization under uncertainty in supply chains ...................................................... 22 


\section{CHAPTER 3. MATHEMATICAL MODEL}

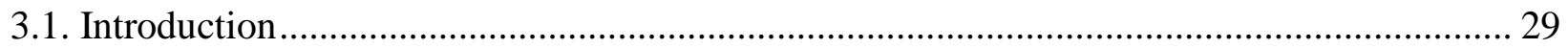

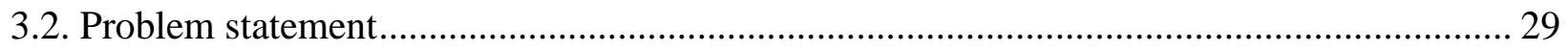

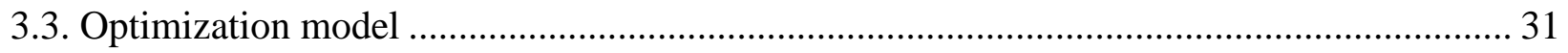

\section{CHAPTER 4. SOLUTION APPROACH}

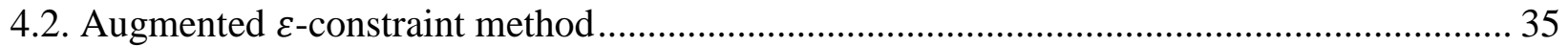

\section{CHAPTER 5. NUMERICAL EXAMPLE}

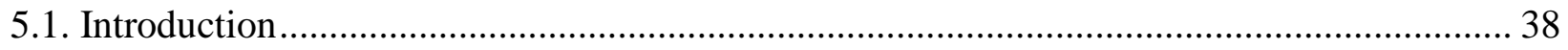

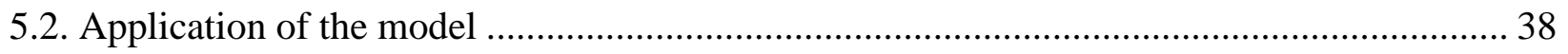

\section{CHAPTER 6: IMPACT OF UNCERTAINTY IN THE PROPOSED MODEL}

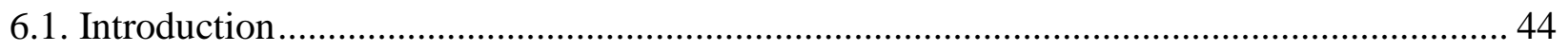

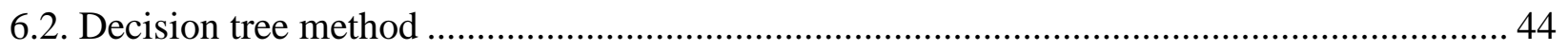

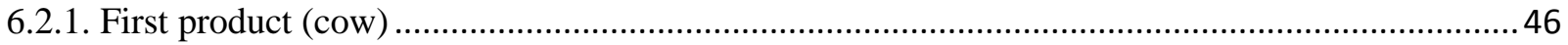

6.2.1.1. Changes in demand and purchasing cost of livestock from farms......................................... 47

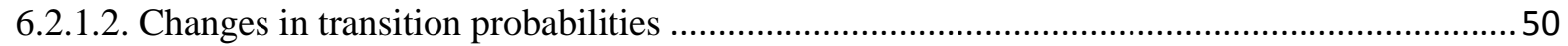

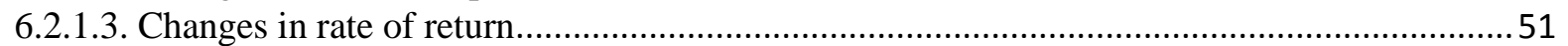

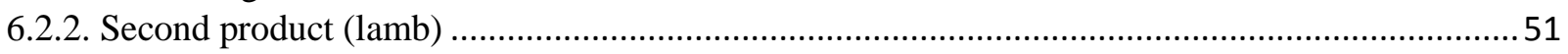

6.2.2.1. Changes in demand and purchasing cost of livestock from farms...................................... 53

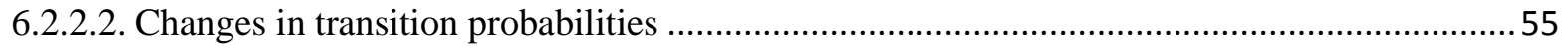

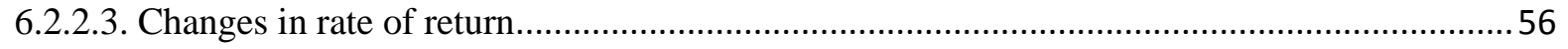

\section{CHAPTER 7. CONCLUSIONS AND FUTURE RESEARCH}

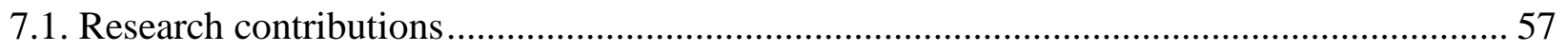

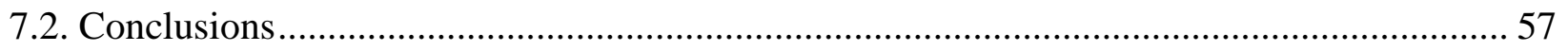

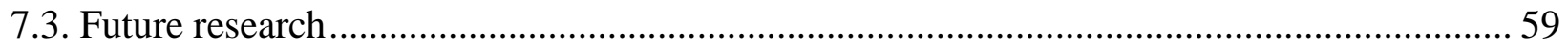

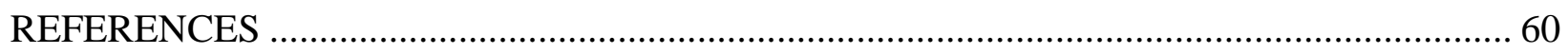




\section{LIST OF TABLES}

\section{CHAPTER 1}

Table 1. 1. Comparing characteristics in traditional and SCM approaches (Cooper and Ellram, 1993)

\section{CHAPTER 2}

Table 2. 1. Review of the literature considering environmental concerns in logistics models..... 28

\section{CHAPTER 5}

Table 5. 1. Values of the parameters defined to solve the mathematical model......................... 40

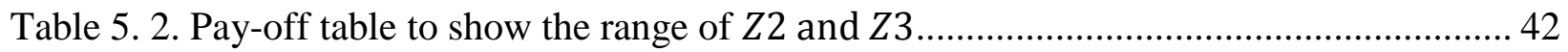

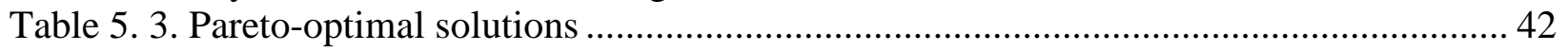

\section{CHAPTER 6}

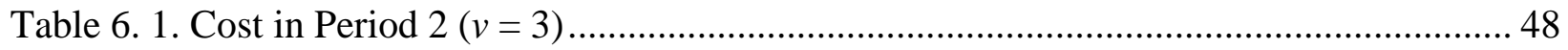

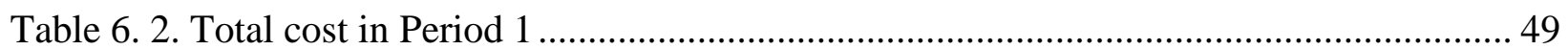

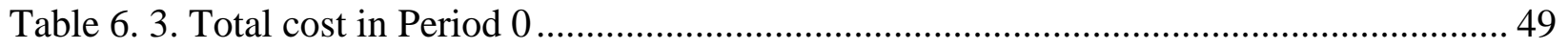

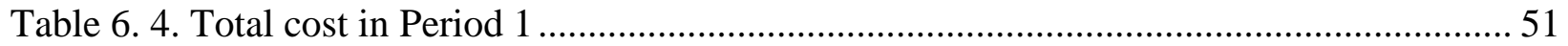

Table 6. 5. Total cost in Period 0 ....................................................................................... 51

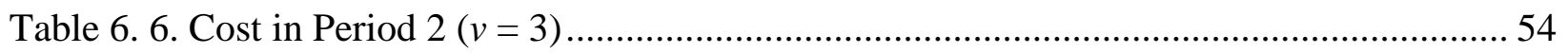

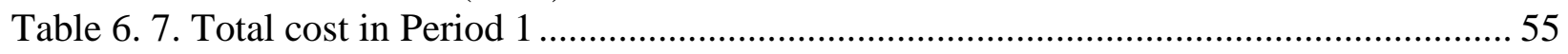

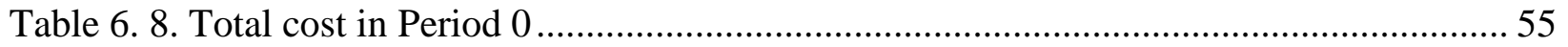




\section{LIST OF FIGURES}

\section{CHAPTER 1}

Figure 1. 1. Waste treatment options (Steven, 2004) ........................................................... 6

Figure 1. 2. A generic model of a closed-loop supply chain (Tonanont et al., 2008)................... 8

Figure 1. 3. Traceability drivers in FSC (Aung and Chang, 2014).......................................... 12

Figure 1. 4. Ontario provincially licensed meat plants (OMAFRA, 2018a).............................. 17

\section{CHAPTER 3}

Figure 3. 1. A four-echelon meat logistics network 30

\section{CHAPTER 5}

Figure 5. 1. Locations of the farms and the retailers are illustrated with blue marks. Locations of the abattoirs and the customers are shown with yellow marks. 41

Figure 5. 2. Pareto-optimal solutions for the multi-objective functions . 43

\section{CHAPTER 6}

Figure 6. 1. Average purchasing cost of livestock from farmers by slaughters for Cows

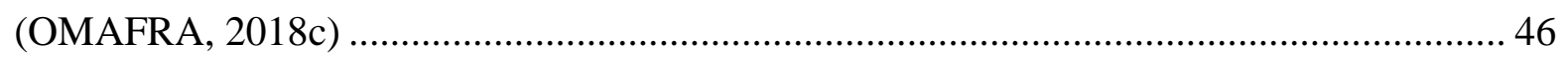

Figure 6. 2. Percentage of purchasing cost changes for Cows (OMAFRA, 2018c) ................... 47

Figure 6. 3. Decision tree (first product)......................................................................... 49

Figure 6. 4. Decision tree considering the new transition probabilities...................................... 50

Figure 6. 5. Average purchasing cost of livestock from farmers by slaughters for Lamb

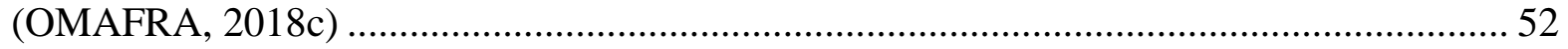

Figure 6. 6. Percentage of perchasing cost changes for Lambs (OMAFRA, 2018c) ................... 52

Figure 6. 7. Decision tree (second product) .................................................................... 54

Figure 6. 8. Decision tree considering new transition probabilities ......................................... 56 


\section{LIST OF ACRONYMS}

Canadian Cattlemen's Association (CCA)

Canadian Pork Council (CPC)

Canadian Meat Goat Association (CMGA)

Canadian Livestock Transport (CLT)

Canadian Food Inspection Agency (CFIA)

Carbon Dioxide $\left(\mathrm{CO}_{2}\right)$

Closed-Loop Supply Chain (CLSC)

Farmers’ Markets Ontario (FMO)

Food Supply Chain Network (FSCN)

Food Supply Chains (FSCs)

Genetic Algorithm (GA)

Greenhouse Gas (GHG)

Goal Programming (GP)

Integer Linear Programming (ILP)

Linear Programming (LP)

Multi-Objective Linear Programming (MOLP)

Mixed-Integer Linear Programming (MILP)

Mixed-Integer Goal Programming (MIGP)

Multi-Objective Fuzzy Programming (MOFP)

Multi-Objective Optimization Model (MOOM)

Non-Linear Multi-Objective Programming (MOP-NL)

Nitrous Oxide $\left(\mathrm{N}_{2} \mathrm{O}\right)$ 
Ontario Ministry of Agriculture, Food and Rural Affairs (OMAFRA)

Ontario Trucking Association (OTA)

Present Value of Total Cost (PVTC)

Quality Function Deployment (QFD)

Return of Investments (ROI)

Supply Chain Management (SCM)

Supply Chain Network (SCN)

Sustainable Supply Chain Management (SSCM)

Sustainable Food Supply Chain Management (SFSCM)

Simulation (Sim)

United Nations Framework Convention on Climate Change (UNFCCC) 


\section{CHAPTER 1. INTRODUCTION}

\subsection{Introduction}

In recent decades, rapid population growth has led to a significant increase in food demand. To handle the high food demand, food supply chain management plays a vital role. In order to be effective, a strong food supply chain network (FSCN) needs to have a cost-effective design that helps make strategic and tactical decisions about the locations and allocation of relevant facilities in the network, as well as the optimal quantities of products that are transported in each echelon of the network. Other factors, such as the quality of food products and safety, also need to be considered in the design of food supply chains (FSCs). These factors are important to customers because they want more transparent information about their daily food consumption (Mohammed and Wang, 2017a).

Environmental concerns are other factors that should be taken into account in the design and configuration of FSCs. One reason to consider them is different environmental protection regulations that have been introduced by governments. These regulations have forced companies to redesign their supply chain networks. Furthermore, different international agreements have been signed between countries to address environmental issues. For instance, the United Nations Framework Convention on Climate Change (UNFCCC) was established in 1992 as a global treaty to reduce greenhouse gas (GHG) emissions. In Canada, this agreement has been enforced since 1994. Every year, Canada prepares a comprehensive report including estimations of different emissions such as carbon dioxide $\left(\mathrm{CO}_{2}\right)$ and nitrous oxide $\left(\mathrm{N}_{2} \mathrm{O}\right)$ in various sectors of the economy, specifically agriculture, energy, waste, and land use. Canada also has a comprehensive plan to reduce GHG, which is called the Pan-Canadian Framework on Clean Growth and Climate Change. According to Environment and Climate Change Canada, 2018, 
Canada’s GHG emissions decreased from 732 megatons of carbon dioxide equivalent in 2005 to 704 megatons of carbon dioxide equivalent in 2016. Canada's lowest level of emissions was in 2009 with 682 megatons of carbon dioxide equivalent. Alberta and Ontario (two provinces in Canada) had the highest level of total emissions in 2005. The emissions were 231 and 205 megatons of carbon dioxide equivalent, respectively. In 2016, Ontario’s emissions decreased by 22\%, reaching 161 megatons of carbon dioxide equivalent, while Alberta's emissions increased by $14 \%$, reaching 263 megatons of carbon dioxide equivalent. The other Canadian provinces, including: Quebec, British Columbia, New Brunswick, Nova Scotia, and Prince Edward Island, decreased their total emissions between 2005 and 2016 by 11\%, 5.1\%, 24\%, 33\%, and 10\%, respectively (Environment and Climate Change Canada, 2018). $\mathrm{CO}_{2}$ is the largest emission contributing to Canada's total emissions. Specifically, 79\% of total emissions in 2016 were $\mathrm{CO}_{2}$ (Environment and Climate Change Canada, 2018). These statistics underscore the importance of minimizing total $\mathrm{CO}_{2}$ emissions as an objective function in addition to considering other objectives in the mathematical models.

\subsection{Supply chain management}

A supply chain includes some facilities that convert raw materials to final products, which are consumed by end-users. The chain usually is started with suppliers, who provide raw materials, and is ended with customers (Sabri and Beamon, 2000). Cooper and Ellram (1993) identified two reasons to form supply chains: reducing investment for inventory and increasing customer service. Different sectors are involved in a supply chain namely, purchasing, manufacturing, inventory, transportation, customer service, and distribution. Integration of all sectors through the flow of materials and information from the first facility in the chain to the end stage is called supply chain management (SCM) (Cooper et al. 1997). Different objectives are achieved when 
SCM is employed in the entire system such as reducing the work in process products, reducing the amount of holding inventory, and increasing the efficient usage of resources (Cooper, 1993).

Different frameworks have been introduced for SCM. The first framework was presented by Cooper and Ellram (1993). The authors defined different characteristics, and compared the traditional approach with the supply chain management approach. Table 1.1 provides a list of the related characteristics, and shows how these characteristics are different in two approaches. The first characteristic is the inventory management, which focuses on eliminating the redundant inventories in the whole channel in the SCM approach. In the traditional approach, each firm has its own inventory management system, independent from other firms in the channel. The next characteristic is total cost, which is managed and controlled in a channel considering all firms in the SCM approach. However, this characteristic is evaluated and controlled by each firm independently, in the traditional approach. The other characteristic is the amount of information that is shared and controlled. In the traditional approach, the exchange of information is based on the needs of the current transaction while in the SCM approach, firms in the channel have enough access to the relevant and required information to conduct their business. In addition, the flow of information and information monitoring are in both directions in the channel, from up to down (manufacturers to retailers) and vice versa. Another characteristic of the SCM approach is to have a chief, who enforces strategies in organizations. However, there is no need to have a chief in the traditional approach. Leaders will manage and resolve the problems. The next characteristic is speed of inventory flow. The main focus of the traditional approach is on storage and increasing the safety stock to meet different customer's demands (warehouse orientation). However, the SCM approach is a distribution center orientation with more focus on inventory velocity in the entire channel. 
Table 1. 1. Comparing characteristics in traditional and SCM approaches (Cooper and Ellram, 1993)

\begin{tabular}{lll}
\hline \multicolumn{1}{c}{ Characteristics } & \multicolumn{1}{c}{ Traditional approach } & \multicolumn{1}{c}{ SCM approach } \\
\hline Inventory management & Independent efforts & Joint reduction in channel inventories \\
Total costs & Minimize firm costs & Channel wide cost efficiencies \\
Time horizon & Short term & Long term \\
Information sharing and & Limited to needs of current & As required for planning and monitoring \\
monitoring & transaction & processes \\
Channel leadership & Not needed & Needed for coordination focus \\
Speed of inventory flow & Warehouse orientation & Distribution center orientation \\
\hline
\end{tabular}

The other framework, which analyzes basic elements of SCM, was introduced by Cooper et al. (1997). The authors presented three elements as follows: the supply chain network structure, the supply chain business processes, and the supply chain management components. The first element, which defines the length of the network, clearly determines which facilities, supply chain members, are involved in the network from the first to the end stage. The second element is categorized into eight processes: customer service management, customer relationship management, demand management, order fulfilment, manufacturing flow management, supplier relationship management, product development management, and returns management. The last element, which determines supply chain management components, defines nine components as follows: planning and control method, work flow structure, organization structure, product flow facility structure, communication and information flow facility structure, management methods, power and leadership structure, risk and reward structure, culture and attitude. The first five components were known as technical and physical components while the last four components were known as behavioral and managerial components. 


\subsection{Different types of supply chains}

There are different types of supply chains such as forward supply chain, reverse supply chain, closed-loop supply chain, and green supply chain.

\subsubsection{Forward supply chain}

This type of supply chain includes all facilities, such as suppliers, manufacturers, distribution centers, and customers, to convert raw materials to a specific final product. The goal is to satisfy customers' demand through combining the flow of materials and information from source, supplier, to end-users (Chopra and Meindl, 2010; Paksoy et al., 2011). In this study, a forward supply chain network in introduced for Ontario’s meat industry.

\subsubsection{Reverse supply chain}

Reverse supply chain has attracted more attentions in recent decades because this type of supply chain helps to take care of end of life products and relieve the environmental concerns. Unlike the forward supply chain, a reverse supply chain is started from end users, who return products. Then, decisions are made for end of life products using different options to recover or dispose products (Govindan et al., 2015). Figure 1.1 shows waste treatment options based on the study conducted by Steven (2004). For example, the remanufacturing option gives an opportunity to firms to resale remanufactured products in the second markets; recycling option helps to have enough raw materials (Govindan et al., 2015). The first step in the remanufacturing process is disassembly, which is the process of removing desired components from the original assembly (Güngör and Gupta, 2002). Different facilities are added to the supply chain network if 
the goal is to develop a reverse supply chain. These facilities can be the recycling centers and the drop-off depots.

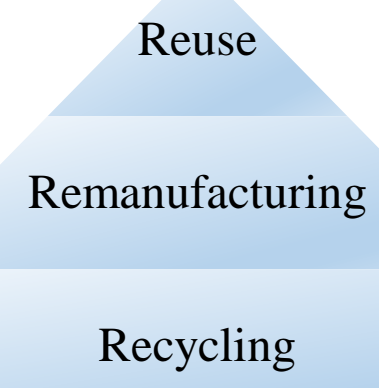

Disposal with energy recovery

Disposal in landfill

Figure 1. 1. Waste treatment options (Steven, 2004)

De Brito and Dekker (2003) discussed about different types of returned products in a reverse supply chain, and categorized them into the following items: manufacturing returns, distribution returns, and customer returns. Manufacturing returns refer to those products that are turned to the production system because of different issues such as quality issues. This type of return includes finished products, and semi-assembled components. Distribution returns occur in the distribution network such as products recall, wrong deliveries, and overstocks such as seasonal products. Customer returns are initiated by customers. Examples are warranty returns, end of use and end of life returns. End of use returns include rented products, leased products, and electronic equipment. Warranty returns include defective household appliances (Fleischmann et al., 2001). 
Fleischmann et al. (2000) compared forward and reverse supply chains, and declared differences between them as follows: First, the quantity of products that are supplied in the forward supply chain is controllable based on the demand, and capacity of facilities. However, the aforementioned quantity is the source of uncertainty in the reverse supply chain because the reuse market's demand is not predictable. Second, the nature of the forward supply chain is based on the pulling system while the reverse supply chain is based on the pushing system. Therefore, the availability of the returned products determines the sequence of the processes that take place in the reverse supply chain. Third, the network structure of reverse supply chain is usually more complex than forward supply chain because of adding more phases, such as inspection and separation, in the reverse supply chain.

\subsubsection{Closed-loop supply chain}

A closed-loop supply chain (CLSC) is resulted from simultaneously combining the forward and reverse supply chains (Govindan et al., 2015). Figure 1.2 illustrates a generic model of a closed-loop supply chain. Solid lines in Figure 1.2 present the forward supply chain while dashed lines present the reverse supply chain. 


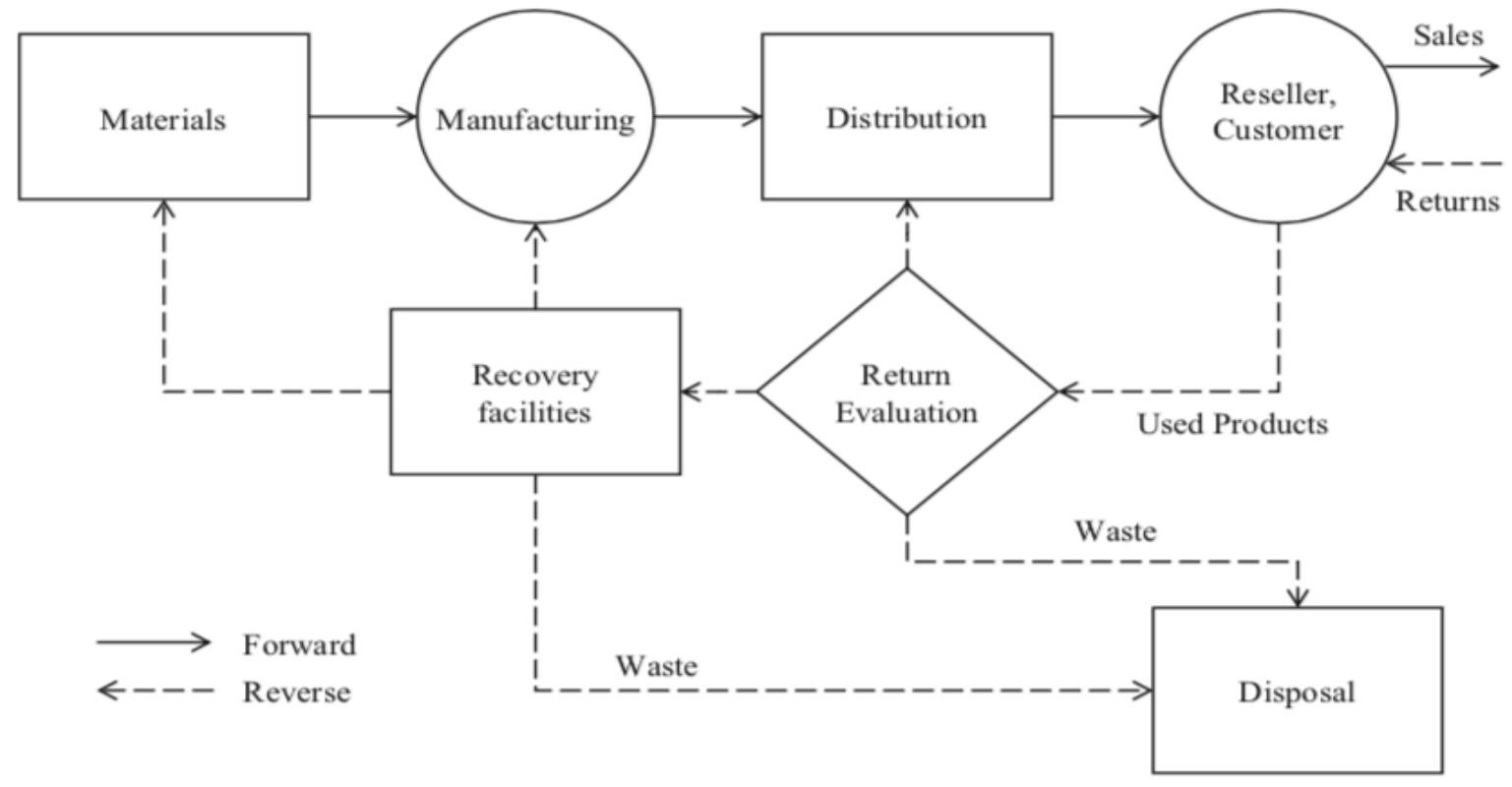

Figure 1. 2. A generic model of a closed-loop supply chain (Tonanont et al., 2008)

\subsubsection{Green supply chain}

A green supply chain is a head of the traditional supply chain by considering the environmental concerns, such as increasing greenhouse gas emissions, in the design of the network. There are different factors that force companies to integrate environmental objectives with economic objectives, and design a sustainable supply chain. These factors may include limited supplies of non-renewable resources (Chaabane et al., 2012), and governmental regulations (Hassini et al., 2012). Sustainable supply chain management (SSCM) focuses on increasing the profit, decreasing the environmental impacts, and increasing the social aspect of the supply chain network (Hassini et al., 2012). Therefore, designing a sustainable supply chain network gives a chance to decision-makers to simultaneously consider conflicting objectives, and make a tradeoff between them. 
Considering sustainability in a food supply chain means reducing the product waste, greenhouse gas emissions, and food miles (Shukla and Jharkharia, 2013). Deduction of food miles (i.e., the number of miles that a product is in the supply chain before reaching to the customer) diminishes different factors such as the amount of consumed fuels in the supply chain, $\mathrm{CO}_{2}$ emissions, and environmental degradation (Van Der Vorst et al., 2009; Shukla and Jharkharia, 2013).

\subsection{Supply chain optimization}

The supply chain optimization is defined as developing the supply chain models to optimize different objectives, such as minimizing the costs, maximizing the profit, and minimizing the delivery time in the supply chain network. Supply chain optimization models consist of a single objective or multiple objectives. In a single objective model, a mathematical model is developed to optimize one objective function while in a multi-objective model, two or more objectives are simultaneously optimized. In this thesis, a multi-objective mathematical model is developed.

\subsection{Food supply chain network}

A food supply chain network (FSCN) is defined as a set of facilities that are involved to produce and distribute fruits, vegetables, and animal-based products (Van Der Vorst et al., 2009). Two types of FSCN were defined by Van Der Vorst et al. (2009) as follows: FSCN for fresh products such as fruits, and FSCN for processed products such as snacks. Different factors affect the design process of a food supply chain network namely, quality requirements, seasonality of production, and storage conditions (Van Der Vorst et al., 2009). Regarding storage conditions, Bartholdi and Hackman (2011) defined perishable warehouses that are usually used to store products with short shelf life such as foods. Efficient utilization of the space is one of the important factors in this type of warehouse. The other significant factor is inventory 
management, which needs to consider different requirements. For example, products need to be shipped based on First-Expired-First-Out or First-In-First-Out. In addition, warehouse temperatures and the way that the products are handled are other important factors that need to be considered for inventory management of perishable warehouses. Appropriate product handing helps to prevent contamination. Globalization, customer awareness about food attributes, and technological innovations have also direct impacts on food supply chains (Shukla and Jharkharia, 2013). For example, globalization has led to increase the distance between food producers and customers. Therefore, the importance of maintaining safety and quality of products is increased in the design of the food supply chain network (Aung and Chang, 2014). Food distribution management is also important because of different factors such as temperature requirements, delivery time restrictions, perishability of products, uncertainties in supply and demands, and customer expectations (Ahumada and Villalobos, 2011).

\subsection{Characteristics of a food supply chain}

In this subsection, the general concepts related to food supply chain are presented.

\subsubsection{Perishability}

Amorim et al. (2013) defined perishability as follows: “A good, which can be a raw material, an intermediate product or a final one, is called perishable if during the considered planning period at least one of the following conditions takes place: its physical status worsens noticeably (e.g., by spoilage, decay or depletion), and/or its value decreases in the perception of a(n) (internal or external) customer, and/or there is a danger of a future reduced functionality in some authority’s opinion”.

Lin et al. (2006) defined two categories for perishability. The first category is called "age- 
dependent on-going deterioration", and the second category is called "age-independent on-going deterioration". Examples for the first group are some fruits such as strawberries while grain products are known in the second group. Perishability aspect of food products affects the supply chain through imposing restrictions on inventory management and distribution (Amorim et al., 2013).

\subsubsection{Shelf life}

Shelf life is defined as a period in which the product keeps its characteristics, such as physical and chemical requirements, remains safe, and preserves its nutritional requirements (Kilcast and Subramaniam, 2000). Shelf life of products has a direct relationship with the perishability of products.

\subsubsection{Freshness and lead time}

Freshness and quality of products are dependent to different aspects of supply chain network (SCN) such as the transportation mode, the amount of time that products are in transit, and the condition of the storage. Therefore, there is an absolute need to manage and optimize production and distribution planning (Soto-Silva et al., 2016). According to the previous studies (Leng and Parlar, 2009; Nair and Lau, 2012), lead time has a direct impact on supply chain management because reducing the supply chain lead time leads to decrease the product waste, low safety stock, small order size, and low costs (Leng and Parlar, 2009; Nair and Lau, 2012).

\subsubsection{Traceability}

Traceability is defined as the ability to obtain all information of the product in different stages of the supply chain with the aim of checking the product safety and quality (Bosona and 
Gebresenbet, 2013). Traceability is an important aspect of FSC because it gives a chance to customers to relieve their concerns related to quality, freshness, and expiry of products. Different benefits have been defined for employing traceability in FSC such as improving the customer's satisfaction (Bosona and Gebresenbet, 2013), reducing the number of labors, who have a direct relationship with information management, through using the electronic systems to record required information, and diminishing costs (Olsen and Borit, 2013).

Bosona and Gebresenbet (2013) defined drivers for traceability as follows: economic, social, and technological concerns. On the other hand, Aung and Chang (2014) defined drivers in more details as Figure 1.3 illustrates.

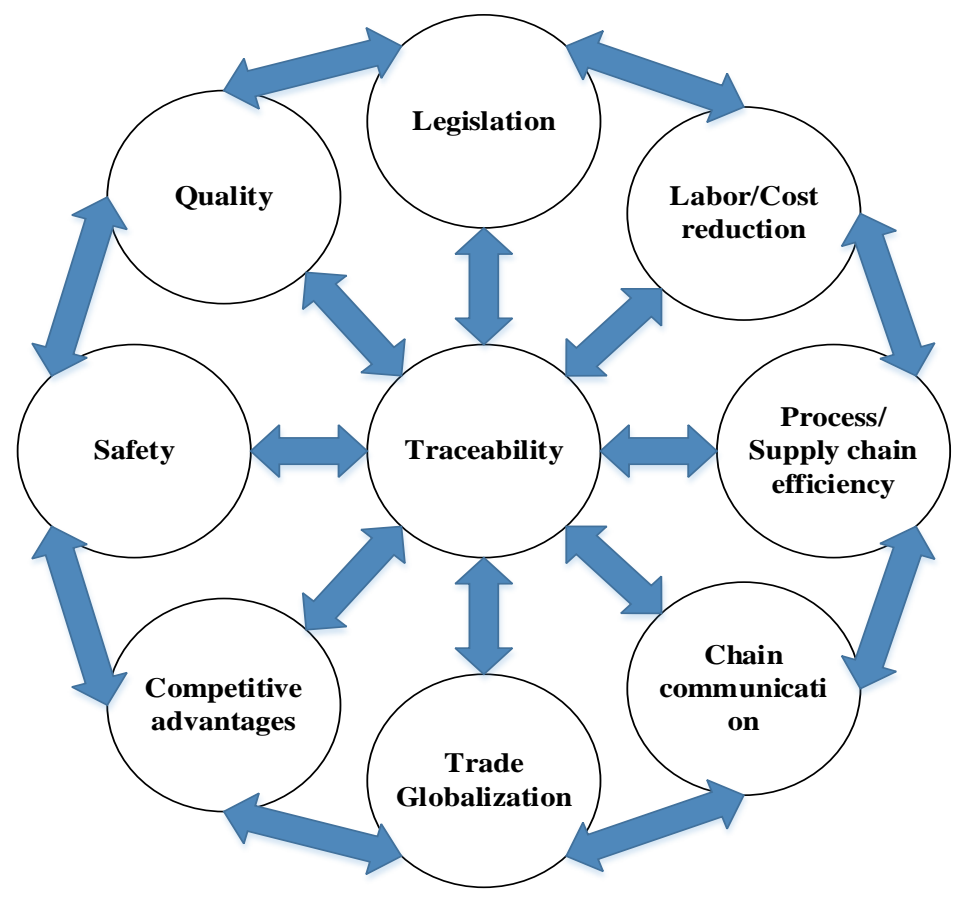

Figure 1. 3. Traceability drivers in FSC (Aung and Chang, 2014) 


\subsection{Food industry in Canada}

In 2014, the food and beverage industry was the second largest manufacturing industry in Canada with the shipment worth of $\$ 105.5$ billion. The meat industry is the largest Canadian food processing industry. In 2014, 25\% of all shipments, which is equal to $\$ 26.3$ billion, accounted for the meat industry (Agriculture and Agri-food Canada, 2017). The Ontario's food and beverage store sales increased from $\$ 42,055,000$ in 2016 to $\$ 43,690,000$ in 2017, approximately 3\% increment of sales value (OMAFRA, 2018d).

The second largest food industry is dairy product manufacturing with 17.3 billion. The other industries in the category of the food and beverage industry are as follows: grain and oilseed milling, beverage manufacturing, bakeries manufacturing, fruits and vegetables, seafood products, and sugar products manufacturing (Agriculture and Agri-food Canada, 2017). Meat industry is the most important food industry in Ontario, Quebec, British Columbia, and Alberta. The biggest sale of the meat production is accounted for Ontario and Quebec with 65\%, which is followed by British Columbia and Alberta with 21\% (Agriculture and Agri-food Canada, 2017). Several factors affect the Canadian food industry such as global market, local demands, and customer's concerns about food safety (House of Commons, 2012). In 2014, 89\% of the total food and beverage products were exported to United States, Mexico, China, Russia, Japan, and South Korea (Agriculture and Agri-food Canada, 2017). This means that there is a good opportunity for Canada to trade the food products in the global markets. Farmers' Markets Ontario (FMO) are public markets that help to relive customer's concerns about food safety because these types of the markets give a chance to customers to directly buy their required foods from farmers. According to Ministry of Agriculture, Food, and Rural Affairs, there are 182 registered farmers' markets in Ontario. 
In the recent decades, people are more interested in organic food products producing with organic farming method, which is a production method without using fertilizers, antibiotics, hormones, and pesticides. To meet organic regulations, organic farms must not use prohibited products and substances such as synthetic fertilizers and pesticides for at least three years before harvesting the organic products (OMAFRA, 2016). "Certified organic” label is used for those food products that are grown in certified organic farms. Based on the organic product regulations, 95\% of certified organic products must be organic ingredients. For organic meat production, livestock are fed with organic feeds such as forages, grains, and protein, which are grown organically (OMAFRA, 2016). In addition, antibiotics, growth hormones, and chemical additives are not used for livestock. Canadian Food Inspection Agency (CFIA) regulates legislations for organic production in Canada. These regulations have been enforced in Canada since June 30, 2009 (OMAFRA, 2017).

\subsubsection{History of Ontario's meat}

In Canada, red meat consists of pork, lamb and mutton, goat, beef and veal, horse, bison, and venison while white meats include chicken, rabbit, turkey, and ducks.

In Ontario, several steps were taken before raising animals in farms. For example, in the 17th century, British started to do farming in Ontario by cleaning the land through cutting trees (Dean, 1994). However, farming was started in Southern Ontario in the 18th century when European people cleaned the land using the human and animal powers (Kelly, 1971). Raising livestock and using production of these animals, such as milk, started from 18th century in Ontario. Up to 1880, 165 butcher shops in Toronto city sold fresh meat to customers (Kheraj, 2013). By 1900, beef as well as cheese were two important farm products, which were exported to the global 
market (McInnis, 1992). In the 20th century, agriculture sector of Ontario had two main features: first, farms were known as mixed-farms with the ability to grow vegetables, grains, and fruits along with raising livestock. Second, farmers were willing to wildly change the type of the farm from a traditional farm growing wheat to meat and dairy farming (Barter, 2014). Some important factors such as increasing local and global demands for meat and dairy products influenced the second feature (Barter, 2014). It should be noted that changing the farm type led to increase the number of slaughters, which mainly focused on killing and processing the cattle and hogs as two important products of meat farming (Barter, 2014).

\subsubsection{Ontario's meat inspection system}

Before 1962, farmers paid to local slaughters or travelling butchers to slaughter their animals. In 1962, all farmers slaughtered their livestock in licensed slaughters (Barter, 2014). Ontario farms' animals are slaughtered and proceed in two types of inspected plants: federal or provincial. Specifically, meats that are sold out of the province are slaughtered in a federal plant while those that are sold within the province are slaughtered in a provincially licensed meat plant. The first federal meat inspection service was established in 1907 when Meat and Canned Foods Act was enforced in Canada. Two important factors to introduce federal inspections were as follows: exporting meats to the global market and increasing public concerns about food safety (Barter, 2014). There are 137 federally inspected meat plants in Ontario (CFIA, 2018).

Provincial licensed meat plants were established at the beginning of 1960s while the provincial meat inspection regulations became mandatory in Ontario by 1969. The Ontario Ministry of Agriculture, Food and Rural Affairs (OMAFRA) is responsible to inspect provincial meat plants. Two types of meat plants exist in the category of provincial plants, which are abattoirs (slaughter 
plants) and freestanding meat plants. The first type of meat plants slaughters animals. They may or may not do further processing of meats while the second type of meat plants just do further processing of meat such as cutting and boning. Figure 1.4 shows the map of provincially licensed meat plants located in Ontario (OMAFRA, 2018a). As indicated in Figure 1.4, a large numbers of abattoirs have been located at Southern Ontario. According to OMAFRA (2018b), 432,526 heads of red meat were slaughtered in provincially inspected meat plants of Ontario from beginning of January 2018 up to end of July 2018. However, the numbers of abattoirs have been decreased since the last decades. In 1998, 267 active abattoirs existed in Ontario (Haines, 2004).

In 2014, the number of abattoirs decreased significantly and reached to 138 abattoirs, approximately 50\% less than those in 1998 (Barter, 2014). In 2018, there are 124 abattoirs in Ontario while 109 out of 124 abattoirs do further processing of meat (OMAFRA, 2018a). This means that there is a reduction of 53\% compared with 1998. Barter (2014) declared some reasons for reduction in the number of abattoirs in the recent decades. One of the main mentioned reasons is decrease in the number of farms in Ontario. Specifically, the number of farms declined from 192,174 in 1931 to 49,600 in 2016 (Statistics Canada, 2006; Statistics Canada, Census of Agriculture, 2017), approximately 74\% reduction during the last 9 decades. Furthermore, the numbers of livestock have been decreased. For example, the total numbers of cattle have had a decline from 1,881,200 in 2008 to 1,613,800 in 2018 (OMAFRA, 2018b). The other reason that was mentioned by Barter (2014) is changing the customer's habits. In the past, people tended to buy their required meats directly from abattoirs, but nowadays they prefer to buy meats from supermarkets (Barter, 2014). 


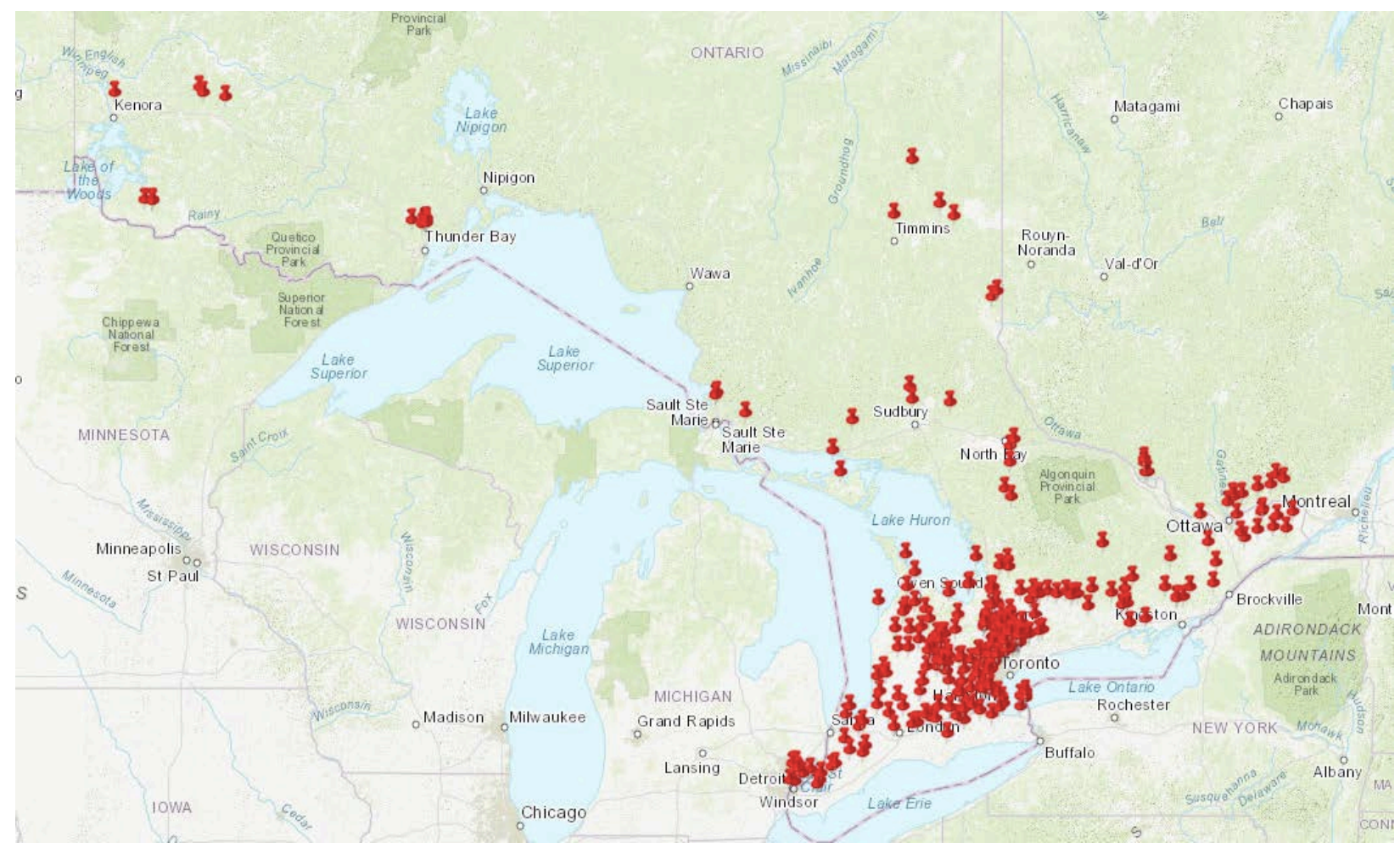

Figure 1. 4. Ontario provincially licensed meat plants (OMAFRA, 2018a)

\subsubsection{Ontario's livestock transportation system}

There are different livestock meat associations in Canada such as Canadian Cattlemen's Association (CCA), Canadian Pork Council (CPC), and Canadian Meat Goat Association (CMGA). In Ontario, Beef Farmers of Ontario is the provincial member association that connects beef producers to CCA. This corporation provides different services to beef farmers such as verifying the cattle age, registering livestock brands on behalf of the OMAFRA, and tracking cattle information such as vaccination. The Canadian Food Inspection Agency (CFIA) regulates the transportation of live animals from a farm to an abattoir. According to CFIA, animals need an approved tag before leaving farms. This is the main requirement for livestock producers (farms) that helps to identify animals and trace them. Some requirements are imposed 
on abattoirs by CFIA such as "abattoir operators must be able to identify the carcasses of livestock in the abattoir; they must also record the identification numbers of the approved and revoked tags of any animals that are slaughtered”. Animal's food, water, and rest time during transportation are some important items that must be considered by the person who transports them. The above required times are various for different species of animals. For example, according to Health of Animals Regulations Part XII: Transportation of Animals-Regulatory Amendment enforced by CFIA, the maximum time intervals without feed, water, and rest is 28 hours for pigs while that time is different for camelids that are 8 days of age or less, only 12 hours. According to CFIA, all animals should rest at least 8 hours with having access to food and water after the maximum time intervals without feed, water, and rest.

One of the big challenges in the livestock transportation industry is a lack of skilled labors and drivers (House of Commons, 2012). Transporting animals requires driving skills to ensure that livestock are moved in a safe manner. There are some training programs for livestock drivers namely, the Canadian Livestock Transport (CLT) training program, which offers a certificate to drivers. The Ontario Trucking Association (OTA) is the only trucking association in Ontario that provides services to trucking companies.

\subsection{Aim and research contributions}

In this research, environmental concerns are integrated with a mathematical model to develop a mixed-integer linear programming model, which is able to optimize three conflicting objectives simultaneously. These objectives are: minimizing total transportation costs and fixed costs, minimizing total $\mathrm{CO}_{2}$ emissions released from transportation, and maximizing total capacity utilization. Our proposed model is able to determine (1) the optimal quantities of products to be transported in every echelon of the network, (2) the optimal quantities of farms, abattoirs, and 
retailers, (3) the locations of farms, abattoirs, and retailers, and (4) how they should be allocated to each other. In the next stage, a solution method, which is augmented $\varepsilon$-constraint is employed to solve the proposed model. Then, decision tree method is utilized to investigate the effects of uncertainty in the presented model.

The main research contributions of this thesis are as follows:

- Developing a new multi-period, multi-product, multi-echelon, and multi-objective mixedinteger linear programming optimization model to design a meat supply chain network in Southern Ontario, Canada. In this model, we consider (a) both economic and environmental goals, (b) final customers as a key factor in the supply chain network, (c) distances between the real locations of the network’s facilities using Google Maps.

- Employing real data to analyze a green meat supply chain network in Ontario, Canada.

- Developing a solution approach based on augmented $\varepsilon$-constraint technique. Based on the developed solution method, we generate Pareto-optimal solutions for decision-makers to consider the trade-off between economic, environmental, and capacity objectives.

- Taking into account the effects of uncertainty in the proposed network based on several decision trees.

To the best of our knowledge, this research is the first investigation that simultaneously considers the aforementioned objectives in a multi-product and multi-period model for a multiechelon green meat logistics network with application in Ontario.

\subsection{Organization of the thesis}

The outline of this thesis is as follows: The related literature is reviewed in Chapter 2. Chapter 3 provides the problem description with the related assumptions. In addition, a multi-period, 
multi-product, and multi-objective mixed-integer linear programming model is introduced in Chapter 3. In Chapter 4, a detailed solution procedure is depicted for the proposed model based on the augmented $\varepsilon$-constraint method. Then, a multi-echelon green meet supply chain network is designed for Southern Ontario in Chapter 5. Chapter 6 investigates the impacts of uncertainty on the proposed model by employing several decision trees. Finally, conclusions and future research directions are discussed in Chapter 7. 


\section{CHAPTER 2. REVIEW OF LITERATURE}

\subsection{Introduction}

In this chapter, existing papers are reviewed in order to better situate this work within the literature. Section 2.2 investigates papers related to multi-objective optimization in FSCs. Optimization under uncertainty in supply chains is reviewed in Section 2.3. Finally, green supply chain networks’ optimization is discussed in Section 2.4.

\subsection{Multi-objective optimization in FSCs}

There are some studies that have applied multi-objective optimization to FSC network design. These objectives have focused on different concerns such as maximization of quality and the safety of products (James et al., 2006; Ahumada and Villalobos, 2009; Akkerman et al., 2010; Rong et al., 2011; Soysal et al., 2012; Rijpkema et al., 2016), or minimization of the total network cost (Villegas et al., 2006; Bhattacharya and Bandyopadhyay, 2010; Cheshmehgaz et al., 2013; Mogale et al., 2018). Paksoy et al. (2012) proposed a multi-objective linear programming formulation to minimize the total transportation cost between different echelons of the supply chain network for vegetable oils. Teimoury et al. (2013) examined the food and vegetable supply chain in Tehran. They proposed a multi-objective formulation, and a solution approach based on simulation.

García-Flores et al. (2014) focused on the meat industry in Northern Australia and formulated a mathematical model to obtain the optimal quantity of products to be transported in different echelons of the network. Their proposed model was also able to determine the optimal location of rest sites for cattle. 
Mohammed and Wang (2015) proposed a multi-objective mathematical model with the aim of maximizing the integrity of Halal meat, minimizing the whole investment expenditure, and maximizing the return of investments (ROI) in a meat supply chain. They employed a Petri-net model, which is a graphical simulation model, to show how their proposed network behaves. Mohammed and Wang (2016) proposed a mixed-integer linear programming formulation to deal with four competing objectives simultaneously: minimizing total cost, and maximizing profits, freshness, and consumer satisfaction.

Mohammed and Wang (2017a) provided a multi-objective model for minimizing the total transportation cost, the number of vehicles in transportation, and the delivery time, in the meat supply chain network. They used three solution approaches, including weighted Tchebycheff, $\varepsilon$ constraint, and LP-metrics techniques, to solve their multi-objective model. Then, they showed that the $\varepsilon$-constraint method outperformed the other two techniques. Mohammed and Wang (2017b) developed a multi-objective formulation in a three-echelon meat logistics network. These objectives included: minimizing the whole cost including transportation costs and implementation costs, maximizing product quality, and maximizing customer satisfaction. Four techniques were applied for solving the model: goal programming, compromise programming, utility function, and weighted Tchebycheff method. The results showed that the compromise programming approach outperformed the other three approaches.

\subsection{Optimization under uncertainty in supply chains}

We reviewed several papers that have utilized multi-objective models in different kinds of supply chain networks. However, the reviewed papers did not consider uncertainty in their models. Decision-making in the real world takes place in an environment with uncertain parameters such as customer's demands and purchasing cost. Therefore, taking the effects of 
uncertainty into account in optimization models helps decision-makers to tackle real-world problems. Several studies were conducted in the past which analyzed the impacts of uncertainty in various logistics networks (e.g., Selim et al., 2008; Torabi and Hassini, 2008; Moheb-Alizadeh et al., 2011; Zarandi et al., 2011; Amin and Zhang, 2012; Liu and Papageorgiou, 2013; Amin and Zhang, 2013; Özceylan and Paksoy, 2013; Özceylan and Paksoy, 2014; Gholamian et al., 2015; Moheb-Alizadeh et al., 2017).

Guillén et al. (2005) developed a mixed- integer multi-objective model considering uncertainty in financial risk and demand parameters to maximize the total profit. Liang (2006) developed a fuzzy based linear programming formulation under uncertainty to minimize the total delivery time and the total distribution cost of food and drinks in Taiwan. Mirzapour et al. (2011) investigated the supply chain of wood and paper in Iran by developing a multi-product, multiperiod, and multi-objective mixed-integer non-linear programming formulation considering two conflicting objectives. The objectives were maximization of customer satisfaction and minimization of total cost. Demand and cost parameters are the sources of uncertainty in their proposed model. They employed the LP-metrics method as a solution method to solve the multiobjective problem. Vahdani et al. (2012) formulated a bi-objective mathematical model to minimize costs in a closed-loop supply chain network under uncertainty of costs, production rate, and facilities' capacities. Then, they employed a hybrid methodology consisting of fuzzy multi objective programming, robust optimization, and queuing theory to solve their proposed model. Mirakhorli (2014) investigated a closed-loop logistics network of bread in Iran by proposing a fuzzy multi-objective linear programming formulation. Demand and return are two main uncertain parameters in this study. The goal was to minimize the total cost and the total transportation time concurrently. The author employed Genetic Algorithm (GA) as the solution 
method to solve the proposed mathematical model. Yang et al. (2015) studied a dairy supply chain formulating a two-stage multi-objective mathematical model, which was solved by a genetic algorithm and a biogeography-based optimization algorithm. Demand and transportation costs are two sources of uncertainty in their proposed model.

Felfel et al. (2016) focused on textile industry, and developed a multi-product, multi-period, and multi-objective linear programming model to optimize three objectives as follows: minimizing the downside risk, minimizing the total cost, and minimizing the lost demand level. Customer demand is the only uncertain parameter that was considered in this study. Azadeh et al. (2017) presented a mixed-integer non-linear programming formulation to investigate the crude oil supply chain in Iran under uncertainty of production capacity, cost, and the consumption rate of petroleum goods produced from crude oil. They employed three solution methods: evolutionary algorithm, genetic algorithm, and particle swarm technique. The obtained results showed that the evolutionary algorithm outperformed the other two solution methods. Mohammed et al. (2017) formulated a multi-objective model to optimize four conflicting objectives: the minimization of the total cost, maximization of the integrity of Halal meat products, maximization of the ROI, and maximization of capacity utilization for Halal meat logistics under uncertainty. They employed the modified weighted-sum and $\varepsilon$-constraint techniques to solve the proposed model. Rahimi et al. (2018) made a trade-off between the present and future profits by introducing a bi-objective and multi-period mixed-integer programming model under uncertainty of demand, selling price, and purchasing cost. They employed LP-metrics method to convert the multi-objective to a single goal model. The effectiveness of their proposed model was shown in a real case study with a well-known food distributer in Iran. Yu et al. (2018) introduced a bi-objective optimization model to investigate 
fresh agri-product under uncertainty of information. Two main objectives in their proposed model are maximization of the customer satisfaction and minimization of the total cost.

\subsection{Green supply chain network optimization}

Overall, the studies discussed above have made notable contributions towards developing optimization models under uncertainty in various supply chain networks. However, they have not taken environmental concerns like greenhouse gas emissions. Environmental factors are equally as important as the economic aspects of supply chain networks (Mohammed and Wang, 2017c). A few studies have integrated these two factors in designing green logistics networks. Soysal et al. (2012) provided a review of sustainable food supply chain management (SFSCM).

Bauer et al. (2010) introduced a mixed-integer linear programming model to minimize the total transportation cost as well as total greenhouse gas emissions for a real-life intermodal freight transport over Austria, Czech Republic, and Poland using AMPL/CPLEX. Chaabane et al. (2012) provided a mixed-integer linear programming formulation to minimize total logistics costs and greenhouse gas (GHG) emissions in a closed-loop supply chain including five layers of the supply chain, which are suppliers, plants, distribution centers, customers, and recycling centers. However, uncertainty was not included in their proposed model.

Soysal et al. (2014) developed a multi-objective linear programming (MOLP) model considering transportation emissions. The goals of their study are to minimize the total logistics costs and the total quantity of $\mathrm{CO}_{2}$ emissions in a beef supply chain network. They employed $\varepsilon^{-}$ constraint method to solve their presented model. However, they did not consider multiple products, they only focused on beef. In addition, the uncertainty effects were not analyzed. Furthermore, customers, which are an important factor to take into consideration, were not addressed. 
Bortolini et al. (2016) focused on fresh food supply chain networks, and developed a multiobjective mathematical formulation with the aim of minimizing operating cost, $\mathrm{CO}_{2}$ emissions, and delivery time of products. However, they did not take uncertainty into account in the model. Mohammed and Wang (2017c) introduced a fuzzy multi-objective programming model to optimize four conflicting objectives in the meat supply chain network: minimizing the whole cost, minimizing the $\mathrm{CO}_{2}$ emissions, minimizing the distribution time of products in each echelon of the network, and maximizing the average delivery rate. Then, they utilized three techniques: goal programming, $\varepsilon$-constraint, and LP-metrics, to solve the proposed model. They showed that $\varepsilon$-constraint method has better performance than the other two solution approaches. However, this study did not consider multiple products, and their proposed model is not multiperiod. In addition, they did not incorporate final customers in their supply chain network, and they only focused on farms, abattoirs, and retailers. Babbar and Amin (2018) developed a twophase model including a quality function deployment (QFD) and a multi-objective model in the beverages industry. The goal of the first phase was supplier selection while the second phase focused on determining order quantity using weighted-sum, $\varepsilon$-constraint, and distance techniques. Five competing objectives were considered in the second phase of their study: minimizing the total cost, minimizing the defect rate, minimizing the carbon emission, maximizing the weight of suppliers, and maximizing on-time delivery.

Table 2.1 provides a summary of related papers that have considered environmental concerns in logistics mathematical models. The research gaps can be identified according to the information in this table. Based on Table 2.1, very few authors have considered environmental concerns in meat industry. It is apparent that the existing papers have not created a comprehensive supply chain network including final customers - which are the main part of a 
meat supply chain network. Furthermore, they did not simultaneously consider multiple products and multiple periods in their models. Considering multiple products in the network design helps to create a comprehensive and cost-effective supply chain network. According to Table 2.1, just a few papers have captured uncertainty in the models. This thesis's primary research contributions, and the features that differentiate our research from other studies, are displayed in the last row of Table 2.1.

In this thesis, several aspects in an integrated manner are considered to simultaneously optimize three competing objectives: minimizing total transportation costs and fixed costs, minimizing total $\mathrm{CO}_{2}$ emissions released from transportation, and maximizing total capacity utilization in each echelon of the network. The combination of these objectives has not been used in previous research studies on the meat industry. Our proposed model is able to determine (1) the optimal quantities of products to be transported in every echelon of the network, (2) the optimal quantities of farms, abattoirs, and retailers, (3) the locations of farms, abattoirs, and retailers, and (4) how they should be allocated to each other. 
Table 2. 1. Review of the literature considering environmental concerns in logistics models

\begin{tabular}{|c|c|c|c|c|c|c|}
\hline Studies & $\begin{array}{l}\text { Model } \\
\text { Type }\end{array}$ & Uncertainty & $\begin{array}{c}\text { Multi- } \\
\text { Product }\end{array}$ & $\begin{array}{l}\text { Multi- } \\
\text { Period }\end{array}$ & $\begin{array}{l}\text { Type of } \\
\text { Products }\end{array}$ & $\begin{array}{c}\text { Real } \\
\text { Location }\end{array}$ \\
\hline Neto et al. (2008) & MOLP & - & $\checkmark$ & - & Pulp, Paper & - \\
\hline Pati et al. (2008) & MIGP & - & $\checkmark$ & - & Paper & - \\
\hline Akkerman et al. (2009) & MILP & - & - & $\checkmark$ & Meals & - \\
\hline Van Der Vorst et al. (2009) & Sim & - & - & $\checkmark$ & Pineapples & - \\
\hline Oglethorpe (2010) & GP & - & - & - & Pork & - \\
\hline Bauer et al. (2010) & MILP & - & - & $\checkmark$ & - & $\checkmark$ \\
\hline Paksoy et al. (2010) & MOLP & - & $\checkmark$ & - & - & - \\
\hline Harris et al. (2011) & Sim & - & - & $\checkmark$ & Automotive & $\checkmark$ \\
\hline Paksoy et al. (2011) & LP & - & $\checkmark$ & - & - & - \\
\hline Bektaş and Laporte (2011) & ILP & - & - & $\checkmark$ & - & - \\
\hline Wang et al. (2011) & MOP-NL & - & $\checkmark$ & - & & $\checkmark$ \\
\hline Chaabane et al. (2011) & MOLP & - & $\checkmark$ & - & Steel & \\
\hline Ubeda et al. (2011) & MILP & - & - & $\checkmark$ & Food & $\checkmark$ \\
\hline Chaabane et al. (2012) & MILP & - & $\checkmark$ & $\checkmark$ & Aluminum & - \\
\hline Elhedhli and Merrick (2012) & MIP-NL & - & - & - & - & - \\
\hline Abdallah et al. (2012) & MILP & - & $\checkmark$ & - & - & - \\
\hline Mallidis et al. (2012) & MILP & - & $\checkmark$ & - & - & $\checkmark$ \\
\hline Pishvaee and Razmi (2012) & MOFP & $\checkmark$ & - & - & Needle, Syringe & - \\
\hline Ruiz-Femenia et al. (2013) & MILP & $\checkmark$ & $\checkmark$ & $\checkmark$ & Petrochemical & $\checkmark$ \\
\hline Harris et al. (2014) & MIP & - & - & - & - & - \\
\hline Soysal et al. (2014) & MOLP & - & - & $\checkmark$ & Beef & $\checkmark$ \\
\hline Validi et al. (2014) & MOO & - & - & - & Milk & $\checkmark$ \\
\hline Bing et al. (2014) & MILP & - & $\checkmark$ & - & Plastic waste & $\checkmark$ \\
\hline Bortolini et al. (2016) & MOLP & - & $\checkmark$ & - & Fruit, Vegetable & $\checkmark$ \\
\hline Talaei et al. (2016) & MILP & $\checkmark$ & $\checkmark$ & - & Copiers industries & - \\
\hline Banasik et al. (2017) & MILP & - & $\checkmark$ & $\checkmark$ & Bread & - \\
\hline Jindal and Sangwan (2017) & MILP & $\checkmark$ & $\checkmark$ & - & - & - \\
\hline Keshavarz et al. (2017) & MOOM & $\checkmark$ & $\checkmark$ & $\checkmark$ & Home appliances & $\checkmark$ \\
\hline Mohammed and Wang (2017c) & MOLP & $\checkmark$ & - & - & Meat & $\checkmark$ \\
\hline Nurjanni et al. (2017) & MILP & - & - & - & - & $\checkmark$ \\
\hline Babbar and Amin (2018) & MILP & - & $\checkmark$ & $\checkmark$ & Beverages & - \\
\hline Pourjavad and Mayorga (2018) & MILP & $\checkmark$ & - & $\checkmark$ & - & - \\
\hline Mohebalizadeh et al. (2018) & MILP & - & $\checkmark$ & $\checkmark$ & Meat & $\checkmark$ \\
\hline This research & MILP & $\checkmark$ & $\checkmark$ & $\checkmark$ & Meat & $\checkmark$ \\
\hline
\end{tabular}

MOLP: multi-objective linear programming; MILP: mixed-integer linear programming; MIGP: mixed-integer goal programming; MOFP: multi-objective fuzzy programming; MOOM: multi-objective optimization model; MOP-NL: non-linear multi-objective programming; ILP: integer linear programming; LP: linear programming; GP: goal programming; Sim: simulation. 


\section{CHAPTER 3. MATHEMATICAL MODEL}

\subsection{Introduction}

The problem statement with different assumptions is declared in Section 3.2. In addition, the proposed multi-echelon meat supply chain network configuration is discussed in Section 3.2. Then, a multi-period, multi-product, and multi-objective mixed-integer linear programming model is introduced in Section 3.3 to optimize three conflicting objectives.

\subsection{Problem statement}

The meat supply chain usually includes three different echelons in the network consisting of farms, abattoirs, and retailers. In this thesis, we add another echelon, customers, to introduce a comprehensive network. Figure 3.1 demonstrates a four-echelon meat logistics network including farms, abattoirs, retailers, and customers. In this network, farms, which have different types of animals, are responsible to supply livestock for abattoirs, where livestock are slaughtered and packed as processed meats. In the next step, meats are transported to retailers who are responsible to sell them to the customers. In this research, we assume that abattoirs make decision to select a farm and a retailer based on different factors. For example, transportation costs and purchasing costs are those factors that are considered to choose a farm. The following assumptions are made to deal with this problem:

- Demand of customers is known in advance, and must be satisfied.

- Maximum capacities of farms, abattoirs, and retailers are known.

- No inventory of meats is allowed in abattoirs or retailers.

- Road transportation mode is selected to transport the products between the chosen facilities in the network. 
- 53-foot tri-axle combination freight livestock trailers (made 2017) are used to transport livestock from farms to abattoirs.

- 53-foot reefer trailers (made 2017) are used to transport meat products from abattoirs to retailers, and from retailers to customers.

- Livestock is slaughtered in the provincial meat plants located in Southern Ontario.

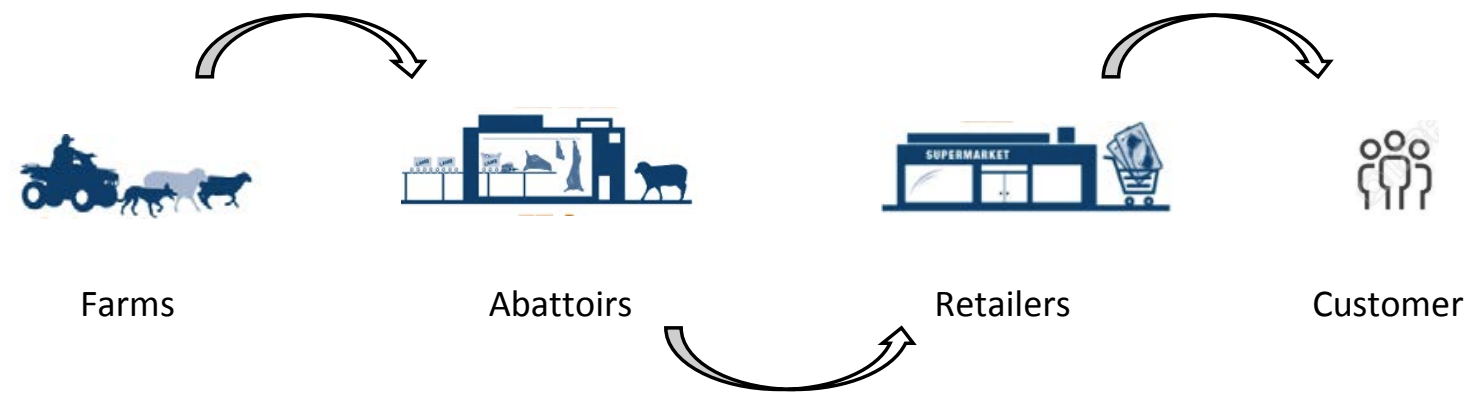

Figure 3. 1. A four-echelon meat logistics network

Both strategic and tactical decisions should be made in this problem. The strategic decisions are employed to determine the locations and allocations of farms, abattoirs, and retailers while the tactical decisions are made to determine the quantities of products that are transported in the proposed meat supply chain network. The outcome of this research answers the following important questions that can assist decision-makers to select a cost-effective supply chain network while considering environmental concerns.

(1) Which farms should be selected?

(2) Which locations should be selected to open abattoirs?

(3) Which retailers should be selected for selling the meat products?

(4) How many products are transported between the selected facilities in the proposed network? 


\subsection{Optimization model}

In this section, a multi-objective mixed-integer linear programming model (MILP) is proposed to optimize the three competing objectives in the green meat logistics network. The details of the MILP model are as follows:

\section{$\underline{\text { Sets }}$}

$F$ : set of potential farms locations $(1 \ldots f \ldots F)$

A: set of potential abattoirs locations $(1 \ldots a \ldots A)$

$R$ : set of potential retailers' locations $(1 \ldots r \ldots R)$

$C$ : set of customers $(1 \ldots c \ldots C)$

$J$ : set of products $j$ including livestock and meat $(1 \ldots j \ldots J)$

$T$ : set of time periods $(1 \ldots t \ldots T)$

\section{$\underline{\text { Parameters }}$}

$p_{f j t}$ : purchasing cost per ton of livestock $j$ from farm $f$ in period $t$

$n_{f}$ fixed-cost for working with farm $f$

$b_{a}$ : fixed-cost for opening abattoir $a$

$e_{r}$ : fixed-cost for selling via retailer $r$

$d e_{f a}$ : transportation distance (mile) from farm $f$ to abattoir $a$

$g e_{a r}:$ transportation distance (mile) from abattoir $a$ to retailer $r$

$h_{r c}$ : transportation distance (mile) from retailer $r$ to customer $c$

$k c_{\text {fajt }}$ : unit transportation cost per mile for livestock $j$ from farm $f$ to abattoir $a$ in period $t$

l $c_{\text {arjt: }}$ unit transportation cost per mile for processed meat $j$ from abattoir $a$ to retailer $r$ in period $t$ $m c_{\text {rcjt: }}$ unit transportation cost per mile for meat $j$ from retailer $r$ to customer $c$ in period $t$ 
$d_{c j t}$ demand (ton) of customer $c$ for meat $j$ in period $t$

$x_{f j}$ : maximum supply capacity (ton) of farm $f$ for livestock $j$

$o_{a j}$ : maximum supply capacity (ton) of abattoir $a$ for processed meat $j$

$u_{r j}$ : maximum supply capacity (ton) of retailer $r$ for meat $j$

$\alpha: \mathrm{CO}_{2}$ emission factor per ton and per mile

$w_{j}$ : weight (ton) of product $j$ including livestock and meat

\section{Decision Variables}

$Q U_{\text {fajt: }}$ quantity of livestock $j$ (ton) transported from farm $f$ to abattoir $a$ in period $t$

$Q N_{\text {arjt: }}$ quantity of processed meat $j$ (ton) transported from abattoir $a$ to retailer $r$ in period $t$

$Q A_{\text {rcjt: }}$ quantity of meat $j$ (ton) transported from retailer $r$ to customer $c$ in period $t$

$Z_{f}$ : binary variable, equals to 1 if farm $f$ is selected, 0 otherwise

$I_{a}$ : binary variable, equals to 1 if abattoir $a$ is open, 0 otherwise

$Y_{r}$ : binary variable, equals to 1 if retailer $r$ is selected, 0 otherwise

\section{Objective Functions:}

$$
\begin{aligned}
& \operatorname{Min} Z_{1}=\sum_{f} \sum_{a} \sum_{j} \sum_{t}\left(p_{f j t}+k c_{f a j t} * d e_{f a}\right) * Q U_{f a j t}+\sum_{a} \sum_{r} \sum_{j} \sum_{t} l c_{a r j t} * g e_{a r} \\
& * Q N_{a r j t}+\sum_{r} \sum_{c} \sum_{j} \sum_{t} m c_{r c j t} * h e_{r c} * Q A_{r c j t}+\sum_{f} n_{f} * Z_{f} \\
&+\sum_{a} b_{a} * I_{a}+\sum_{r} e_{r} * Y_{r} \\
& \operatorname{Min} Z_{2}=\alpha\left(\sum_{f} \sum_{a} \sum_{j} \sum_{t} w_{j} * d e_{f a} * Q U_{f a j t}+\sum_{a} \sum_{r} \sum_{j} \sum_{t} w_{j} * g e_{a r} * Q N_{a r j t}\right. \\
&\left.+\sum_{r} \sum_{c} \sum_{j} \sum_{t} w_{j} * h e_{r c} * Q A_{r c j t}\right)
\end{aligned}
$$


$\operatorname{Max} Z_{3}=\sum_{f} \sum_{a} \sum_{j} \sum_{t} Q U_{f a j t} / x_{f j}+\sum_{a} \sum_{r} \sum_{j} \sum_{t} Q N_{a r j t} / o_{a j}+\sum_{r} \sum_{c} \sum_{j} \sum_{t} Q A_{r c j t} / u_{r j}$

$S . T$

$\sum_{a} \sum_{j} Q U_{\text {fajt }} \leq Z_{f} \cdot \sum_{j} x_{f j} \quad \forall f, t$

$\sum_{r} \sum_{j} Q N_{\text {arjt }} \leq I_{a} \cdot \sum_{j} o_{a j} \quad \forall a, t$

$\sum_{c} \sum_{j} Q A_{r c j t} \leq Y_{r} \cdot \sum_{j} u_{r j} \quad \forall r, t$

$\sum_{f} Q U_{f a j t} \geq \sum_{r} Q N_{\text {arjt }} \quad \forall a, j, t$

$\sum_{a} Q N_{\text {arjt }} \geq \sum_{c} Q A_{r c j t} \quad \forall r, j, t$

$\sum_{r} Q A_{r c j t}=d_{c j t} \quad \forall c, j, t$

$Z_{f}, I_{a}, Y_{r} \in\{0,1\} \quad \forall f, a, r, c, j, t$

$Q U_{\text {fajt }}, Q N_{\text {arjt }}, Q A_{\text {rcjt }} \geq 0 \quad \forall f, a, r, c, j, t$

The first objective $\left(Z_{1}\right)$ minimizes the total transportation costs and the fixed costs. The first part is related to the purchasing cost and transportation cost of livestock that are sent from farms to abattoirs. The second and third parts of the objective function consider transportation cost of meats sending from abattoirs to retailers and from retailers to customers, respectively. The other parts are related to the fixed costs associated with farms, abattoirs, and retailers. The second 
objective function $\left(Z_{2}\right)$ minimizes $\mathrm{CO}_{2}$ emissions released from transportation. The last objective function $\left(Z_{3}\right)$ maximizes capacity utilization of facilities. It's first part considers capacity utilization of farms while the second and third parts take into account the capacity utilization of abattoirs, and retailers, respectively. Constraints (3.1), (3.2), and (3.3) satisfy capacity limitations of farms, abattoirs, and retailers, respectively. Constraints (3.4) and (3.5) declare that input meats and output meats should be equal in each abattoir and each retailer, respectively (for each product in each time period). Constraint (3.6) satisfies demands of each customer for each product. Constraints (3.7) and (3.8) define binary variables and non-negative variables, respectively. 


\section{CHAPTER 4. SOLUTION APPROACH}

\subsection{Introduction}

Different solution methods have been developed in the literature to solve multi-objective problems (e.g., Paksoy et al., 2012; Bortolini et al., 2016; Moheb-Alizadeh and Handfield, 2017). In this study, augmented $\varepsilon$-constraint method, which is an improved version of traditional $\varepsilon$ constraint technique, is employed to convert the presented multi-objective model to a single one. Different steps to employ the aforementioned method is discussed in Section 4.2.

\subsection{Augmented $\varepsilon$-constraint method}

The traditional $\varepsilon$-constraint method, which was introduced by Chankong and Haimes (1983), optimizes one objective function when the rest of the objective functions are considered as constraints with proper upper or lower bounds. These bounds, which are altered to obtain the Pareto solutions, are different levels of $\varepsilon$. This method was employed in a large number of studies (Amin and Zhang, 2013; Soysal et al., 2014; Mohammed et al., 2017). However, augmented $\varepsilon$-constraint method, which was introduced by Mavrotas (2009), has attracted attention of researchers in recent years because of some advantages. This method can guarantee the efficiency of the Pareto-optimal solutions. In addition, this method can reduce the computational time when researchers have to solve problems with more than two objective functions (Mavrotas, 2009). Some studies have applied the improved version of the traditional $\varepsilon$ constraint method (Ahmadi et al., 2012; Mavrotas and Florios, 2013; Ramos et al., 2014; Felfel et al., 2016). The augmented $\varepsilon$-constraint method is utilized to solve a multi-objective model through the following steps (Mavrotas, 2009): 
- Step 1: Choosing one objective function as the main objective. In this research, we consider the cost objective, $Z_{1}$, as the main objective function.

- Step 2: Generating a payoff table to find the range of the objectives that are transferred into constraints. To meet this goal, the maximum and minimum values of every objective should be calculated. In this study, the emission objective, $Z_{2}$, as well as the capacity objective, $Z_{3}$, are transferred into constraints. Then, the range of each objective is obtained by calculating the global optimal solution of each objective and replacing the obtained value in the rest of the objective functions. In this way, we will have three values, which help us to determine the maximum and minimum values of every objective.

- Step 3: Dividing the range of each objective to $q$ equal intervals, which leads to having $(q+1)$ grid points for each objective function. Each grid point provides a sub-problem that needs to be solved. The result is one Pareto-optimal solution for each sub-problem.

- $\quad$ Step 4: Changing the form of the proposed model as follows:

\section{$\operatorname{Min} Z_{1}$}

s.t.

$Z_{2} \leq Z_{2(\min )}+v \cdot \Delta \varepsilon_{z_{2}}$

$Z_{3} \geq Z_{3(\min )}+v \cdot \Delta \varepsilon_{z_{3}}$

Where $v=0,1,2, \ldots, q, \Delta \varepsilon_{Z_{2}}=\left(\frac{Z_{2(\max )}-Z_{2(\min )}}{q}\right)$, and $\Delta \varepsilon_{Z_{3}}=\left(\frac{Z_{3(\max )}-Z_{3(\min )}}{q}\right)$.

- Step 5: Transforming the objective function constraints of the above model to equalities by adding proper slack or surplus variables in order to guarantee the efficiency of the obtained solutions. In addition, the slack and surplus variables are added to the main 
objective. Furthermore, the other constraints are considered in this step. Therefore, we will have:

$\operatorname{Min}\left(Z_{1}+\beta \cdot\left(S_{1}+S_{2}\right)\right)$

s.t.

$Z_{2}+S_{1}=Z_{2(\min )}+v \cdot \Delta \varepsilon_{Z_{2}} \quad v=0,1,2, \ldots, q$

$Z_{3}-S_{2}=Z_{3(\min )}+v \cdot \Delta \varepsilon_{z_{3}} \quad v=0,1,2, \ldots, q$

Where $\beta$ is a very small number usually among $10^{-3}$ and $10^{-6}$. However, $\beta$ does not have any impact on the value of the main objective function (Mota et al., 2015). The values of $S_{1}$ and $S_{2}$ should be equal to zero or very close to zero in order to have an efficient Pareto optimal solution (Felfel et al., 2016).

It should be noted that there is no single solution that simultaneously optimizes the three aforementioned objectives. Therefore, trade-offs between different objectives are considered based on the set of Pareto-optimal solutions, which are calculated from applying the augmented $\varepsilon$-constraint technique. The optimality of the Pareto solutions is guaranteed when there is no better feasible solution that can improve some objectives without deteriorating the rest of the objectives at the same time (Coello and Romero, 2003). 


\section{CHAPTER 5. NUMERICAL EXAMPLE}

\subsection{Introduction}

In Section 5.2, the efficiency of the proposed mathematical model is investigated by applying the proposed optimization model to design and optimize a green meat supply chain network in Southern Ontario, Canada.

\subsection{Application of the model}

To show the behavior of the proposed model in Section 3.3, a multi- echelon green meat supply chain network is designed in this section. The locations of different facilities have been shown in Figure 5.1. There are 15 potential farms located at Bradford, Lakeside, Stevensville, Chatsworth, Sarnia, Chatham, Ayton, Hamilton, Simcoe, Highgate, Ashfield-ColborneWawanosh, Leamington, Staffa, Caledon, and Etobicoke. 12 provincially licensed meat plants have been chosen as abattoirs, which are Townsend Butchers Inc. located at Simcoe city, ENS Poultry Inc. located at Elora city, Mount Brydges Abattoir Ltd. located at Mount Brydges city, Country Meadow Meats located at Owen Sound city, Beeton Meats located at Beeton city, Gord's Abattoir Ltd. located at Leamington city, Weiland Meats Market located at Petrolia, Walkerton Meat Market located at Walkerton, Niagara Sausage and Meat Products Limited located at Welland, Atwood Heritage Processing Inc. located at Atwood, Millgrove Packers Limited located at Waterdown, and Off The Bone Meat Products Ltd. located at Mississauga. In addition, there are 21 retailers: Walmart stores located at Vaughan, Windsor, Hamilton, Sarina, and Niagara Falls; No-frills stores located at Guelph and Mount Forest; Food basics located at Strathroy, Scarborough, Toronto, Kitchener, and Brantford; the beef way (butcher shop) located at Tiverton; Metro located at Barrie, Owen Sound, Tillsonburg; Loblaws located at Bowmanville 
and Collingwood; Real Canadian superstore located at Chatham; Freshco located at Cambridge, and Foodland located at Clinton. Furthermore, 20 cities in Southern Ontario are selected as customers: Toronto, Hamilton, London, Kitchener, Windsor, Sarnia, Owen Sound, ChathamKent, Brantford, Barrie, Oshawa, Niagara, Guelph, Cambridge, Waterloo, Hanover, Clinton, Minto, Tillsonburg, and Collingwood. Google Maps are used to calculate the real distances between different locations. Two products including cow and lamb have been chosen for this application. Weights of the products are considered according to the information provided by OMAFRA. Three time periods are considered in this example. Therefore, $T=3$. The length of each period is assumed to be one week.

The purchasing cost of livestock from farms is based on the average prices that Ontario livestock farmers received for slaughter of different types of meats in 2017. Interested readers are referred to Statistics Canada 2017. The demand of each customer for each product is assumed to be 0.01 of the population of the city, which is based on the 2016 Census data, provided by Statistics Canada 2017. The Canadian dollar is considered as a common currency. As we assumed before, the heavy-duty vehicles, which are tri-axle combination freight livestock trailers and reefer trailers made 2017, are used to transport livestock and meat products, respectively, between different locations. The maximum transportation capacity of trailers to transport livestock is equal to $55,000 \mathrm{lbs}$. or $24,500 \mathrm{~kg}$. This type of trailers is classified under Class 8 heavy-duty vehicles. It should be noted that every vehicle has a $\mathrm{CO}_{2}$ emissions rate that must not exceed the pre-defined $\mathrm{CO}_{2}$ emissions standard. In this research, the amount of $\mathrm{CO}_{2}$ emissions standard, $\alpha$, is determined based on the Heavy-duty Vehicle and Engine Greenhouse Gas Emission regulations under the Canadian Environmental Protection Act, 1999 issued on April 14, 2012, and amended 2015-07-16. Based on the above regulation, $\alpha$ is equal to 222 grams per 
ton-mile for vehicles that transport livestock. Moreover, the maximum transportation capacity of a reefer trailer is $44,000 \mathrm{lbs}$. or $20,000 \mathrm{~kg}$. Therefore, this type of trailer is classified under Class 8 heavy-duty vehicles. Hence, the same $\mathrm{CO}_{2}$ emissions standard rate, $\alpha=222$ grams per tonmile, is used for this type of trailer. Table 5.1 provides the values of the parameters that have been utilized in this application.

Table 5. 1. Values of the parameters defined to solve the mathematical model

\begin{tabular}{lll}
\hline$F=15$ & $k c_{f a j t}=l c_{a r j t}=m c_{r c j t}=0.005$ & $d_{131 t}=d_{132 t}=1.317$ ton \\
$A=12$ & $d_{11 t}=d_{12 t}=27.316$ ton & $d_{141 t}=d_{142 t}=1.299$ ton \\
$R=21$ & $d_{21 t}=d_{22 t}=5.369$ ton & $d_{151 t}=d_{152 t}=1.049$ ton \\
$C=20$ & $d_{31 t}=d_{32 t}=3.838$ ton & $d_{161 t}=d_{162 t}=0.074$ ton \\
$J=2$ & $d_{41 t}=d_{42 t}=2.332$ ton & $d_{171 t}=d_{172 t}=0.030$ ton \\
$n_{f}=10,000$ & $d_{51 t}=d_{52 t}=2.172$ ton & $d_{181 t}=d_{182 t}=0.086$ ton \\
$e_{r}=20,000$ & $d_{61 t}=d_{62 t}=0.716$ ton & $d_{191 t}=d_{192 t}=0.158$ ton \\
$\alpha=222$ grams per ton-mile & $d_{71 t}=d_{72 t}=0.318$ ton & $d_{201 t}=d_{202 t}=0.217$ ton \\
$w_{1}=0.635$ ton & $d_{81 t}=d_{82 t}=1.016$ ton & $x_{f 1}=x_{f 2}=15$ ton \\
$w_{2}=0.041$ ton & $d_{91 t}=d_{92 t}=0.974$ ton & $o_{a 1}=o_{a 2}=15$ ton \\
$b_{a}=1,000,000$ & $d_{101 t}=d_{102 t}=1.414$ ton & $u_{r 1}=u_{r 2}=15$ ton \\
$p_{f 1 t}=\$ 1,649.5$ per ton & $d_{111 t}=d_{112 t}=1.594$ ton & \\
$p_{f 2 t}=\$ 5,574.6$ per ton & $d_{121 t}=d_{122 t}=1.331$ ton & \\
\hline
\end{tabular}

The augmented $\varepsilon$-constraint method is coded using LINGO 17 software on a $1.8 \mathrm{GHz}$ laptop computer to solve the mathematical model. The generated pay-off information to obtain the range of the objectives, $Z_{2}$ and $Z_{3}$, is written in Table 5.2. Based on Table 5.2, $Z_{2(\min )}$ is equal to $1,016 \mathrm{~kg}$ while $Z_{2(\max )}$ is equal to $21,358 \mathrm{~kg}$. Therefore, the range of this objective function is between $1,016 \mathrm{~kg}$ and $21,358 \mathrm{~kg}$. The same process is done for $Z_{3}$. The next step is to divide the 
range of $Z_{2}$ and $Z_{3}$ to $q$ equal intervals. In this research, $q$ is equal to 8 . Therefore, we will have 9 grid points, which means that 9 Pareto-optimal solutions will be generated. It should be noted that the larger number of $q$ can generate denser efficient solutions with more computational time (Mavrotas, 2009). In the next stage, we change the form of the proposed mathematical model as was explained in Steps 4 and 5 in Section 4.2. Table 5.3 includes the set of Pareto-optimal solutions obtained from solving the proposed model by the augmented $\varepsilon$-constraint method using LINGO 17.

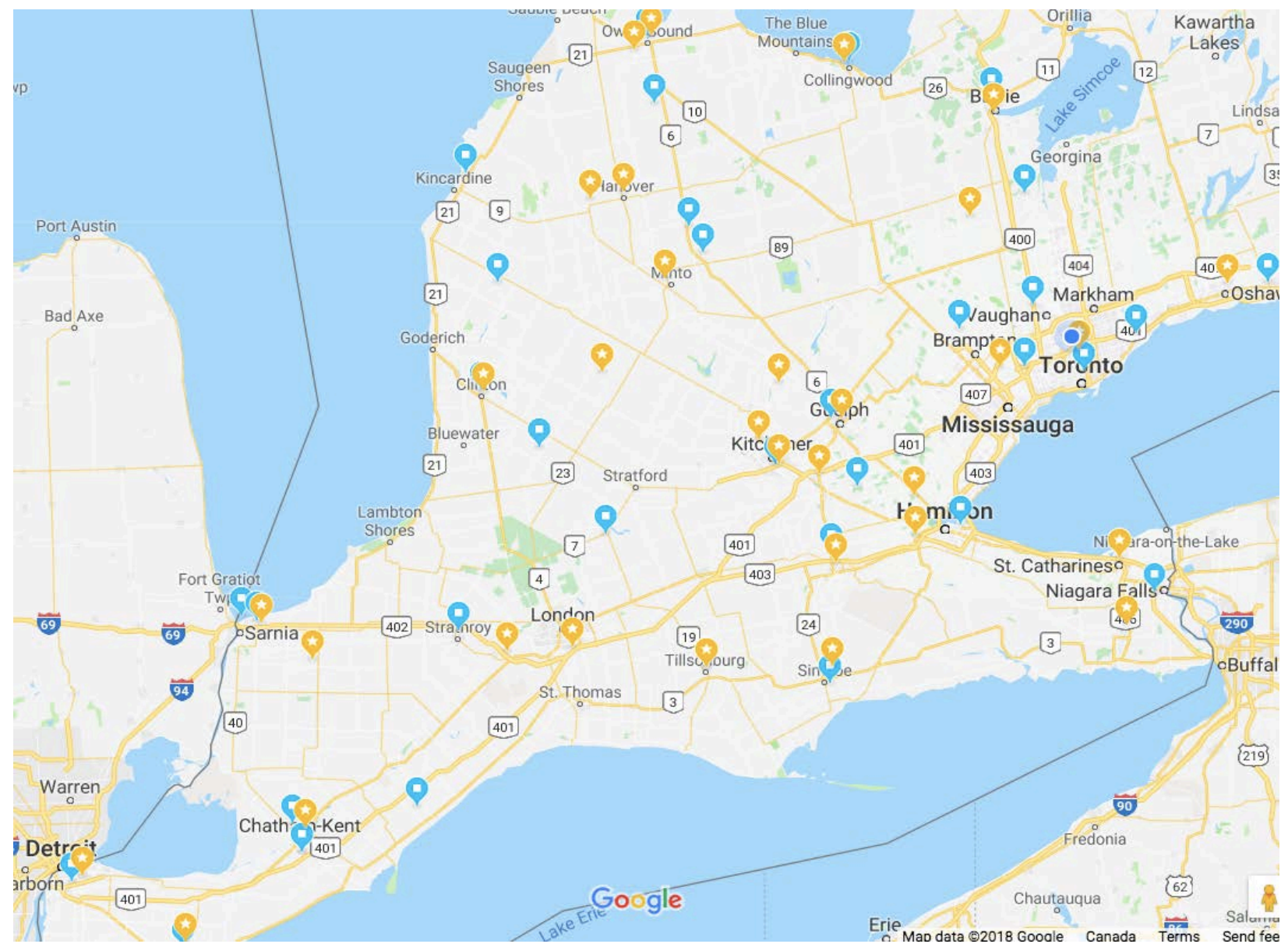

Figure 5. 1. Locations of the farms and the retailers are illustrated with blue marks. Locations of the abattoirs and the customers are shown with yellow marks. 
This set gives a chance to decision-makers to make trade-offs between different objective functions, and choose the preferred solution. Based on the results in Table 5.3, the emission objective has its minimum value when $v=0$; the cost objective has the minimum value when $v=$ 1 , while the capacity objective has its maximum value when $v=8$. Particularly, the results indicate that improving the capacity objective by approximately $190 \%$ deteriorates the environmental objective by 2,002\%; and improving the capacity objective by approximately 134\% deteriorates the economic objective by $170 \%$. Figure 5.2 illustrates a comparison between the three objectives in terms of obtained Pareto-optimal solutions. As Figure 5.2 shows, all objectives have growing trend when $v$ is increased. The model is solved in 10.34 seconds when $v$ $=0$ while the computational time is 27 seconds when $v=8$. There are 5,164 variables including 48 integer variables, 467 constraints, 40,014 non-zero elements for both values of $v$.

Table 5. 2. Pay-off table to show the range of $Z_{2}$ and $Z_{3}$

\begin{tabular}{lcc}
\hline Objective function & $Z_{2}(\mathrm{~kg})$ & $Z_{3}$ (ton) \\
\hline Minimize $Z_{1}$ & 1,421 & 63.14 \\
Minimize $Z_{2}$ & 1,016 & 63.14 \\
Maximize $Z_{3}$ & 21,358 & 183.04 \\
\hline
\end{tabular}

Table 5. 3. Pareto-optimal solutions

\begin{tabular}{cccc}
\hline$v$ & $\begin{array}{c}\text { Cost } \\
(\$)\end{array}$ & $\begin{array}{c}\text { Emission } \\
(\mathrm{kg})\end{array}$ & $\begin{array}{c}\text { Capacity } \\
\text { (ton) }\end{array}$ \\
\hline 0 & $11,560,470$ & 1,016 & 63.144 \\
1 & $5,578,361$ & 3,559 & 78.132 \\
2 & $5,979,292$ & 6,101 & 93.12 \\
3 & $6,370,222$ & 8,644 & 108.108 \\
4 & $6,771,153$ & 11,187 & 123.096 \\
5 & $8,003,629$ & 13,730 & 138.084
\end{tabular}




\begin{tabular}{cccc}
6 & $10,929,190$ & 16,273 & 153.072 \\
7 & $13,003,220$ & 18,815 & 168.06 \\
8 & $15,077,240$ & 21,358 & 183.048 \\
\hline
\end{tabular}

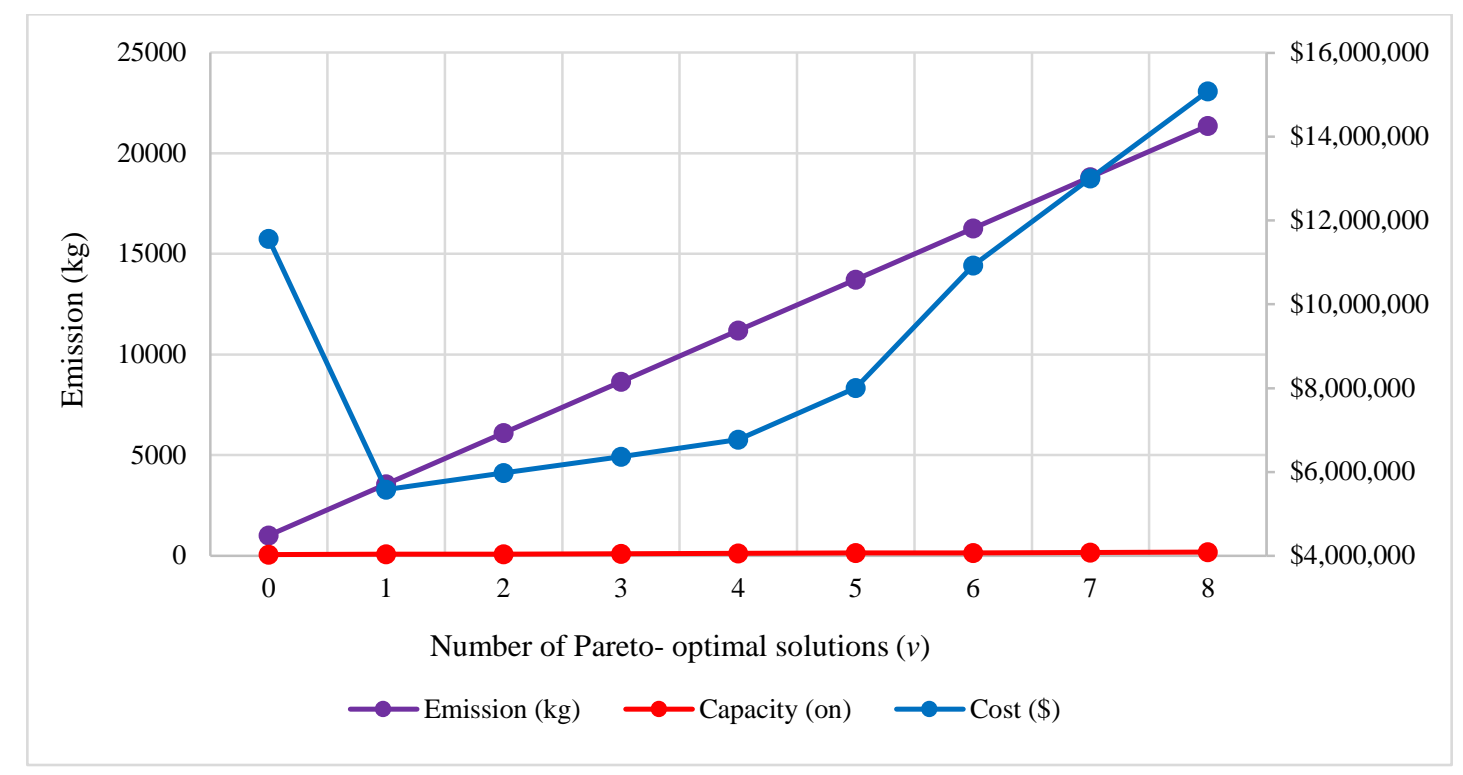

Figure 5. 2. Pareto-optimal solutions for the multi-objective functions 


\section{CHAPTER 6. IMPACT OF UNCERTAINTY IN THE PROPOSED MODEL}

\subsection{Introduction}

The proposed mathematical model in Section 3.3 is a multi-period model without considering uncertainty. However, tackling the real-world problems needs to consider uncertain parameters. In Section 6.2, the multi-period model is converted to a single period in order to consider uncertainty in financial factors in different periods. Then, several decision trees are utilized to analyze the effects of uncertainty in the problem.

\subsection{Decision tree method}

In this research, a solution approach, which is called decision tree, is employed to investigate how uncertainty affects the proposed model. Different studies employed the decision tree method to analyze uncertainty (Nepal and Yadav, 2015; Mogre and D'Amico, 2016; Abdi and Labib, 2017; Amin et al., 2017). The steps of the decision tree method are as follows (Chopra and Meindl, 2015):

1. Determining the number of time periods in the future and duration of each period. In this research, three periods (Period 0, Period 1, and Period 2) are considered. The duration of each period is one year.

2. Identifying the sources of uncertainty in the network. Purchasing cost of livestock from farms and customers' demand are two sources of uncertainty in this study.

3. Identifying a transition probability, which is the probability of moving forward from Period $h$ to Period $h+1$. Different transition probabilities are taken into account in this research to see how this factor can affect the proposed model. 
4. Determining the discount rate, $d r$, which is the rate of return of money in the future in each period. This rate helps to obtain the present value of future cash flow using the discount factor, $d f$, which is obtained through the following formula:

$$
d f=\frac{1}{1+d r}
$$

5. Drawing the decision tree for predefined periods considering multiple nodes in each period. Each node consists of a combination of the values for uncertain parameters. Nodes are connected from Period $h$ to Period $h+1$ by arrows. The transition probabilities are written on top of each arrow.

6. Evaluating the decision tree starting from the last period and moving back to the first period.

First, a single period multi-objective mixed-integer linear programming model is solved by employing the augmented $\varepsilon$-constraint method. As a result, Pareto-optimal solutions are generated. Then, the solution of $v=3$ is chosen as the best solution considering the trade-offs between the three objectives. In the next step, the model is solved by the augmented $\varepsilon$-constraint method for each node of Period 2 while $v=3$. As explained before, the cost objective is considered as the main objective while the rest of the objectives are transferred to the constraints. This process helps to obtain the total cost for each node of the last period. Then, the expected cost of each node of Period 2, G, is calculated. Following this step, the total cost moved from Period 2 to Period $1, K$, is calculated considering the discount factor. It should be noted that the total cost for each node of Period $1, C$, needs to be obtained using the augmented $\varepsilon$-constraint technique to solve the single period and multi-objective mixed-integer linear programming model. The whole cost of Period 1 is obtained through the summation of $K$ and $L$. The same 
process is utilized to obtain the whole cost of Period 0, which is called the Present Value of Total Cost (PVTC).

Different scenarios, which are considered for each product, are defined to investigate the effects of uncertainty. They are as follows:

a. Changes in demand and purchasing cost of livestock from farms.

b. Changes in transition probabilities.

c. Changes in rate of return.

\subsubsection{First product (cow)}

According to OMAFRA (2018c), the average purchasing cost of livestock has been increased significantly from 2008 to 2017. Figure 6.1 shows the growing trend of the mentioned parameter. Figure 6.2 illustrates the percentage of purchasing cost changes for cows based on Figure 6.1. According to Figure 6.2, the average of changes in the percentage of purchasing cost for cows is $10 \%$.

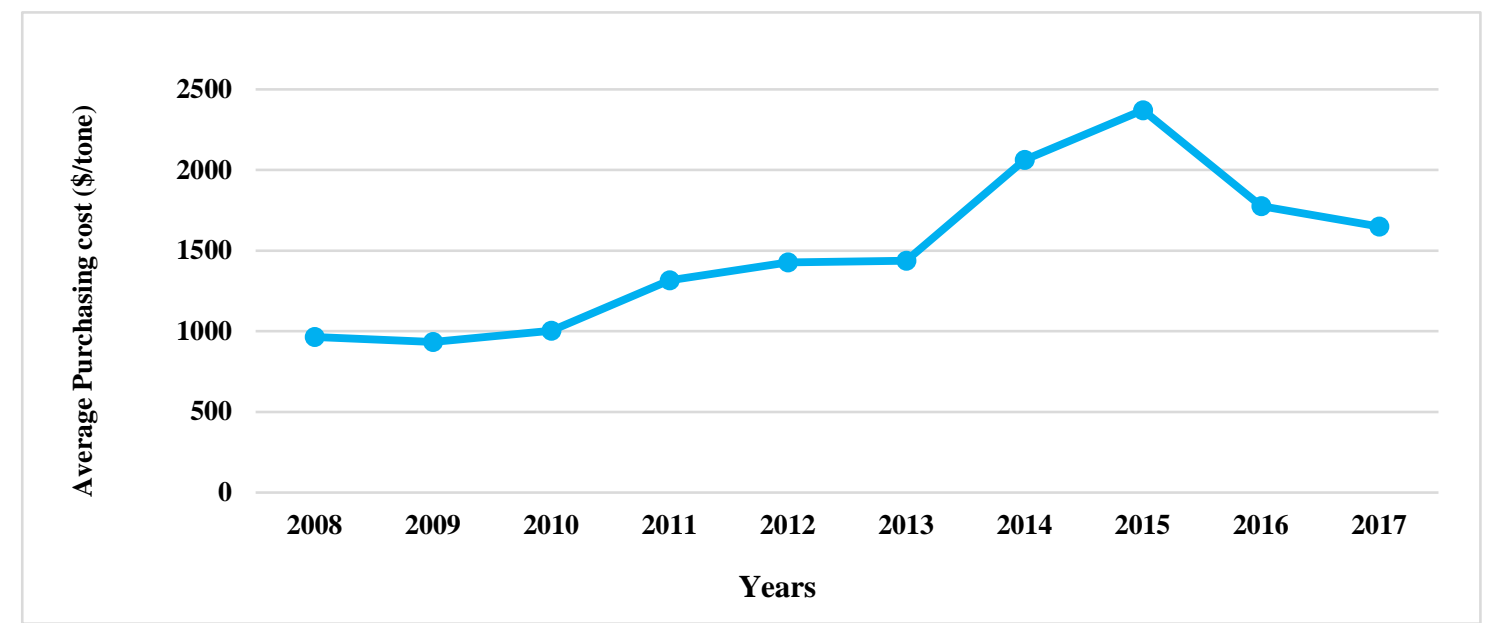

Figure 6. 1. Average purchasing cost of livestock from farmers by slaughters for Cows (OMAFRA, 2018c) 


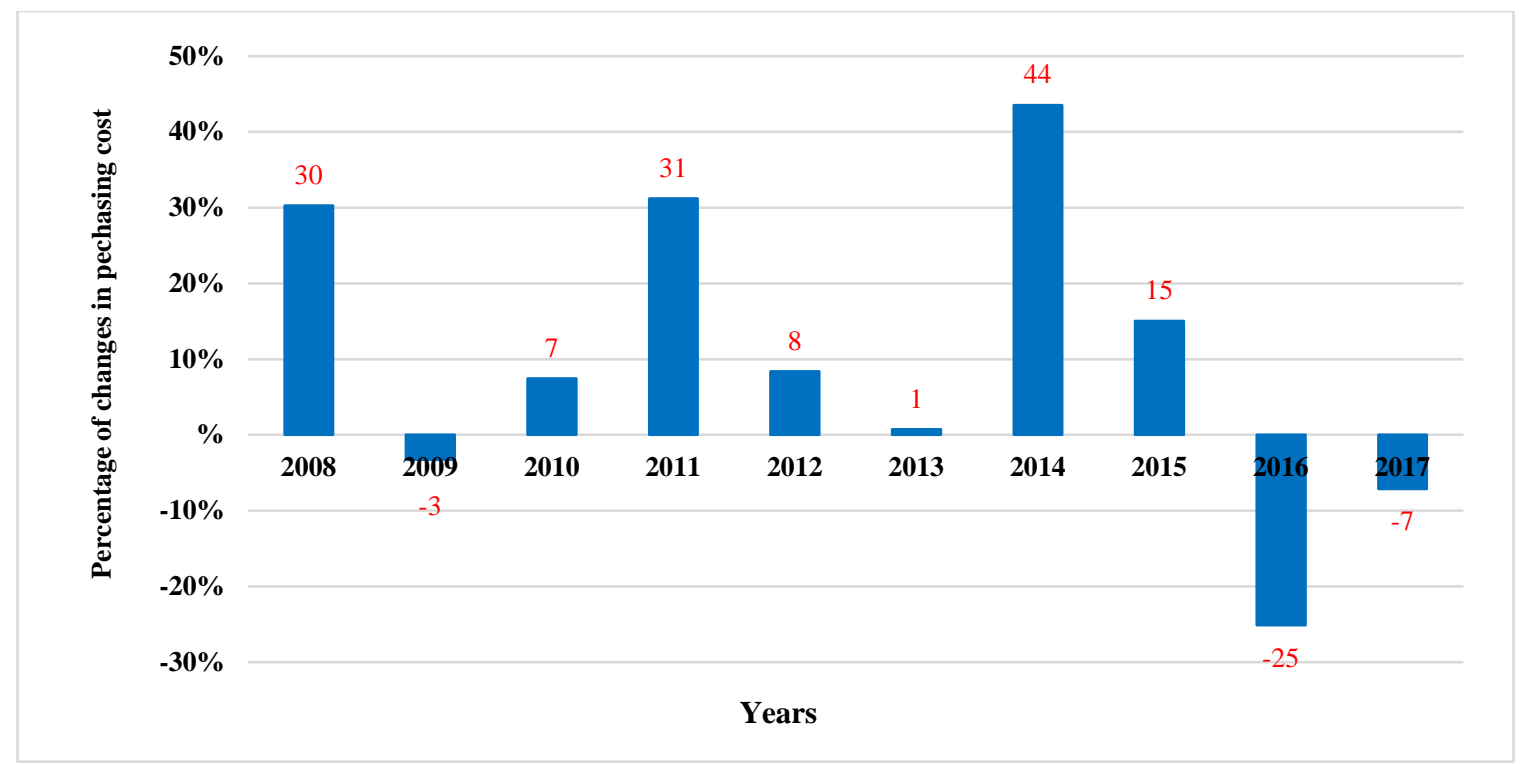

Figure 6. 2. Percentage of purchasing cost changes for Cows (OMAFRA, 2018c)

\subsubsection{Changes in demand and purchasing cost of livestock from farms}

In this subsection, the effects of uncertain parameters, which are purchasing cost of livestock from Ontario farmers and customers' demand, are investigated on the single period model. It is assumed that the demand increases or decreases by $20 \%$ with the probability of 0.5 for the first product (Cow) for all customers. As was explained in the previous subsection, the purchasing costs of livestock increase or decrease by $10 \%$ with the probability of 0.5 . The discount rate, $d r$, is considered 0.1 for each year.

Figure 6.3 shows the decision tree including nodes with different values of demand and purchasing cost, and the transition probabilities, which are $0.5 * 0.5=0.25$ for each arrow. Table 6.1 includes the obtained cost values for each node of Period 2. These results obtained through employing the augmented $\varepsilon$-constraint technique for solving the single period and multiobjective mixed-integer linear programming model for each node of Period 2 while $v=3$. 
Table 6.2 contains the total cost in Period 1. For example, the expected cost in Period 2, $g=$ $0.25 \times(5,901,661+5,825,623+4,915,857+5,011,947)=5,413,772$. The cost from Period 2 moved to Period $1, K=5,413,772 / 1.1=4,921,611$. Then, the value of $L$ is obtained through using the augmented $\varepsilon$-constraint technique to solve the single period multi-objective mixedinteger linear programming model for each node of Period 1 . Therefore, the total cost of Period 1 is summation of $K$ and $L$, which is equal to 9,862,604. Similar calculations are used to obtain the total cost in Period 0 (see Table 6.3). Finally, Present Value of Total Cost $($ PVTC) $=4,916,741$ $($ cost of Period 0$)+8,533,211($ cost moved from Period 1 to Period 0$)=13,449,952$. The PVTC values help decision-makers to choose the best option (less cost) considering uncertainty when they are facing to design different supply chain networks.

Table 6. 1. Cost in Period $2(v=3)$

\begin{tabular}{cc}
\hline Node & Cost $(\$)$ \\
\hline $1.2 d_{1}, 1.1 p_{1}$ & $5,901,661$ \\
$1.2 d_{1}, 0.9 p_{1}$ & $5,825,623$ \\
$0.8 d_{1}, 0.9 p_{1}$ & $4,915,857$ \\
$0.8 d_{1}, 1.1 p_{1}$ & $5,011,947$ \\
$1.2 d_{1}, 1.1 p_{2}$ & $5,825,623$ \\
$0.8 d_{1}, 1.1 p_{2}$ & $4,915,857$ \\
$0.8 d_{1}, 0.9 p_{2}$ & $4,837,237$ \\
$1.2 d_{1}, 0.9 p_{2}$ & $5,763,410$ \\
$1.2 d_{2}, 1.1 p_{1}$ & $5,011,947$ \\
$1.2 d_{2}, 0.9 p_{1}$ & $4,915,857$ \\
$0.8 d_{2}, 1.1 p_{1}$ & $4,105,433$ \\
$0.8 d_{2}, 0.9 p_{1}$ & $3,992,346$ \\
$1.2 d_{2}, 1.1 p_{2}$ & $4,915,857$ \\
$1.2 d_{2}, 0.9 p_{2}$ & $4,837,237$ \\
$0.8 d_{2}, 1.1 p_{2}$ & $3,992,346$ \\
$0.8 d_{2}, 0.9 p_{2}$ & $3,899,819$ \\
\hline
\end{tabular}




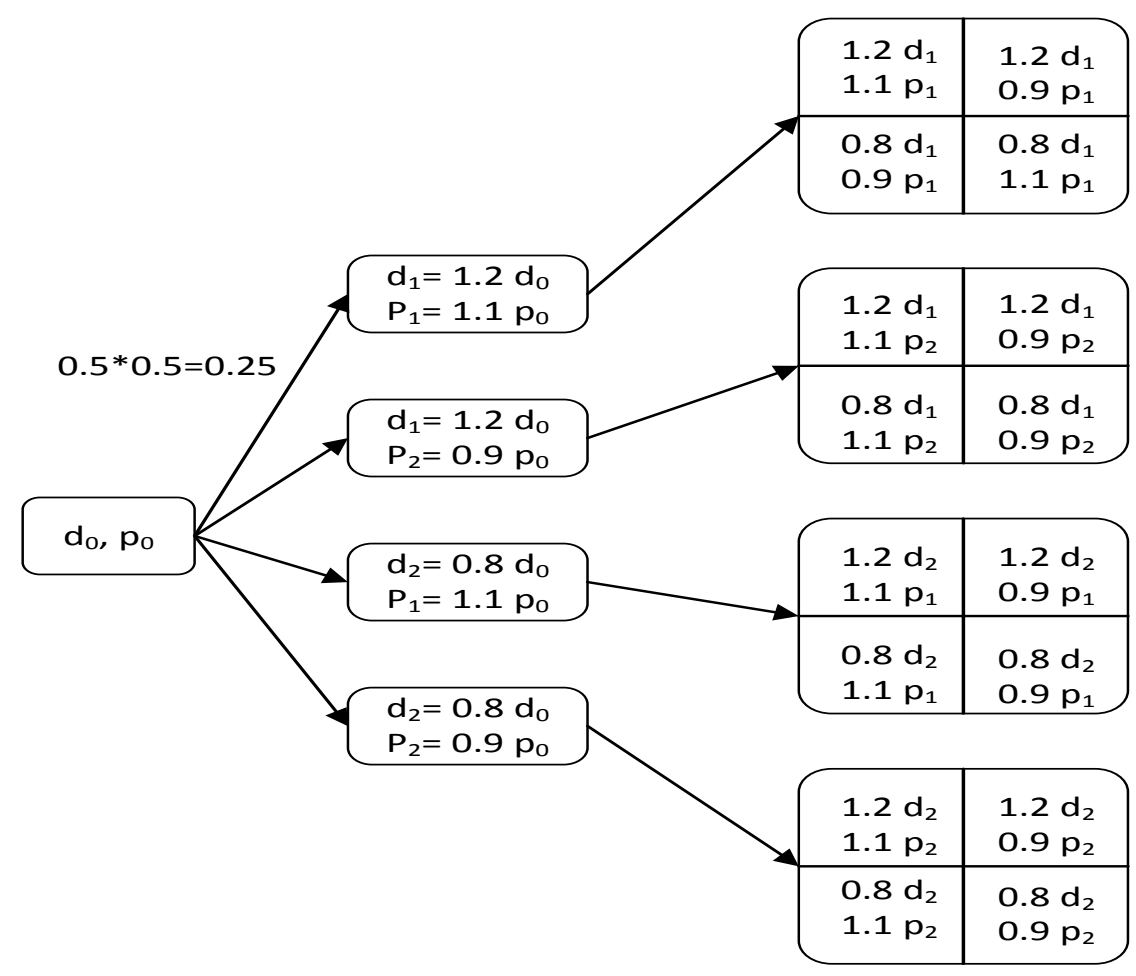

Figure 6. 3. Decision tree (first product)

Table 6. 2. Total cost in Period 1

\begin{tabular}{ccccc}
\hline Node & $\begin{array}{c}\boldsymbol{G}=\text { Expected cost in } \\
\text { Period 2 }\end{array}$ & $\begin{array}{c}\boldsymbol{K}=\text { Cost from Period 2 } \\
\text { in Period 1 = (G/1 + dr) }\end{array}$ & $\begin{array}{c}\boldsymbol{L}=\text { Cost of } \\
\text { Period 1 }\end{array}$ & $\begin{array}{c}\boldsymbol{K}+\boldsymbol{L}=\text { Total cost of } \\
\text { Period 1 }\end{array}$ \\
\hline $1.2 d_{0}, 1.1 p_{0}$ & $5,413,772$ & $4,921,611$ & $4,940,993$ & $9,862,604$ \\
$1.2 d_{0}, 0.9 p_{0}$ & $5,335,532$ & $4,850,483$ & $4,857,803$ & $9,708,286$ \\
$0.8 d_{0}, 1.1 p_{0}$ & $4,506,396$ & $4,096,723$ & $4,979,181$ & $9,075,904$ \\
$0.8 d_{0}, 0.9 p_{0}$ & $4,411,315$ & $4,010,286$ & $4,889,048$ & $8,899,334$ \\
\hline
\end{tabular}

Table 6. 3. Total cost in Period 0

\begin{tabular}{ccccc}
\hline Node & $\begin{array}{c}\boldsymbol{M}=\text { Expected cost in } \\
\text { Period 1 }\end{array}$ & $\begin{array}{c}\boldsymbol{Q}=\text { Cost from Period 1 } \\
\text { in Period 0 = }(\boldsymbol{M} / \mathbf{1}+\boldsymbol{d} \boldsymbol{r})\end{array}$ & $\begin{array}{c}\boldsymbol{S}=\text { Cost of } \\
\text { Period 0 }\end{array}$ & $\begin{array}{c}\boldsymbol{Q}+\boldsymbol{S}=\text { Total cost of } \\
\text { Period 0 }\end{array}$ \\
\hline$d_{0}, p_{0}$ & $9,386,532$ & $8,533,211$ & $4,916,741$ & $13,449,952$ \\
\hline
\end{tabular}




\subsubsection{Changes in transition probabilities}

In this subsection, the probabilities of increase or decrease in demands and purchasing costs are changed to see how the probabilities can affect the model. The probability of increase in uncertain parameters is considered 0.6 while the probability of decrease is assumed 0.4 . Figure 6.4 illustrates the decision tree considering the new transition probabilities. Tables 6.4 and 6.5 include the obtained results. The new PVTC is 13,619,768, which shows that changing one unit of transition probabilities can increase the PVTC by $1,698,161$ because $(13,619,768$ $13,449,952) /(0.6-0.5)=1,698,161$. The main reason for the above increment is because the expected cost in period 2, $G$, is increased. This leads to increase the total cost of Period $1, K+L$, and following that, the expected cost in Period 1, $M$.

\section{Period 0}

Period 1

Period 2

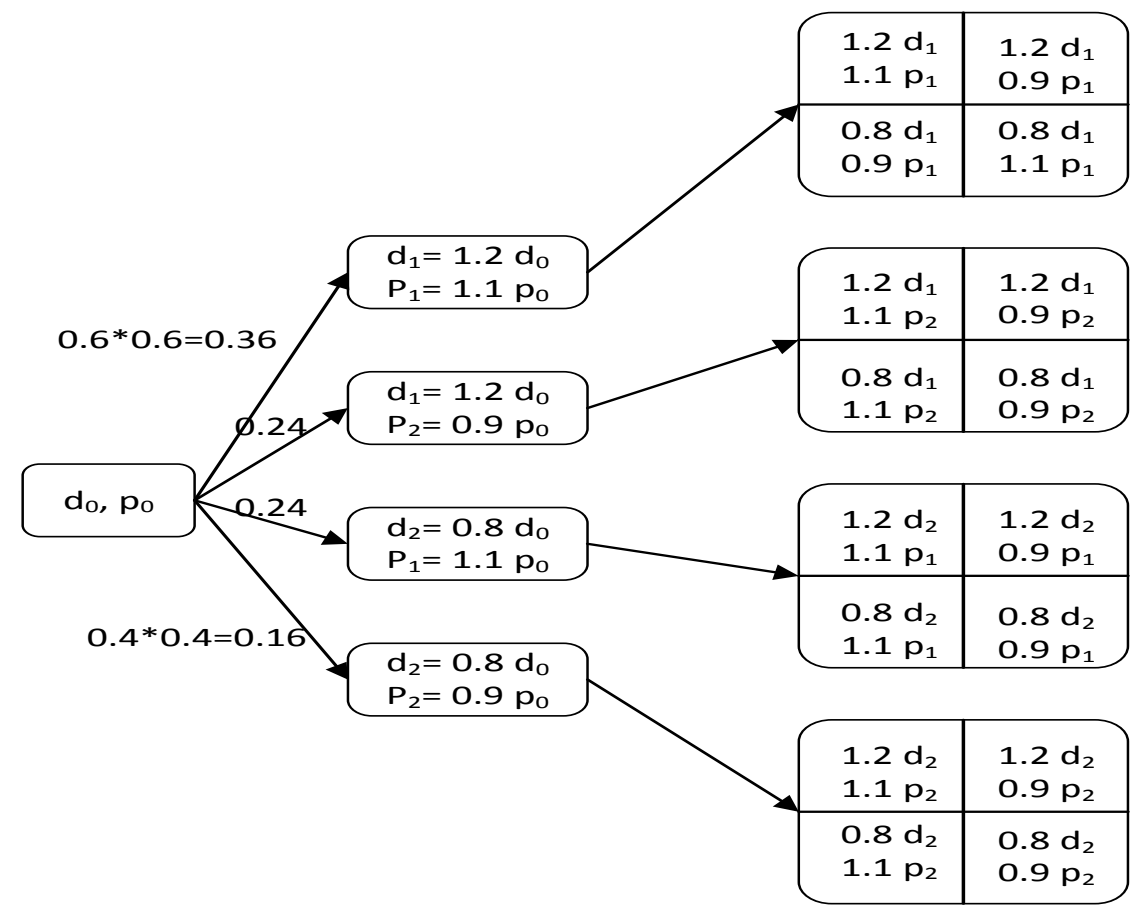

Figure 6. 4. Decision tree considering the new transition probabilities 
Table 6. 4. Total cost in Period 1

\begin{tabular}{ccccc}
\hline Node & $\begin{array}{c}\boldsymbol{G}=\text { Expected cost in } \\
\text { Period 2 }\end{array}$ & $\begin{array}{c}\boldsymbol{K}=\text { Cost from Period 2 in } \\
\text { Period 1 = (G/1 + dr) }\end{array}$ & $\begin{array}{c}\boldsymbol{L}=\text { Cost of } \\
\text { Period 1 }\end{array}$ & $\begin{array}{c}\boldsymbol{K}+\boldsymbol{L}=\text { Total cost of } \\
\text { Period 1 }\end{array}$ \\
\hline $1.2 d_{0}, 1.1 p_{0}$ & $5,512,152$ & $5,011,047$ & $4,940,993$ & $9,952,040$ \\
$1.2 d_{0}, 0.9 p_{0}$ & $5,434,206$ & $4,940,188$ & $4,857,803$ & $9,797,991$ \\
$0.8 d_{0}, 1.1 p_{0}$ & $4,608,186$ & $4,189,260$ & $4,979,181$ & $9,168,441$ \\
$0.8 d_{0}, 0.9 p_{0}$ & $4,512,779$ & $4,102,527$ & $4,889,048$ & $8,991,575$ \\
\hline
\end{tabular}

Table 6. 5. Total cost in Period 0

\begin{tabular}{ccccc}
\hline Node & $\begin{array}{c}\boldsymbol{M}=\text { Expected cost in } \\
\text { Period 1 }\end{array}$ & $\begin{array}{c}\boldsymbol{Q}=\text { Cost from Period 1 in } \\
\text { Period 0 }=(\boldsymbol{M} / \mathbf{1}+\boldsymbol{d} \boldsymbol{r})\end{array}$ & $\begin{array}{c}\boldsymbol{S}=\text { Cost of } \\
\text { Period 0 }\end{array}$ & $\begin{array}{c}\boldsymbol{Q}+\boldsymbol{S}=\text { Total cost of } \\
\text { Period 0 }\end{array}$ \\
\hline$d_{0}, p_{0}$ & $9,573,330$ & $8,703,027$ & $4,916,741$ & $13,619,768$ \\
\hline
\end{tabular}

\subsubsection{Changes in rate of return}

In this subsection, the discount rate, $d r$, is changed from 0.1 to 0.15 . The rest of the parameters are remained the same, which means that the demand increased or decreased by $20 \%$ while the purchasing cost increased or decreased by $10 \%$ with the transition probability of 0.5 . The new PVTC is $12,909,953$, which shows that increasing in the rate from 0.1 to 0.15 diminishes the PVTC by 539,999 because $(12,909,953-13,449,952) /(0.15-0.1)=-539,999$. The main reason for the above decrease is because the cost from Period 2 in Period $1, K$, is diminished. This leads to decrease the total cost of Period $1, K+L$, and following that, the expected cost in Period $1, M$.

\subsubsection{Second product (lamb)}

According to Ontario Ministry of Agriculture, Food and Rural Affairs (2018), the average purchasing cost of livestock has increased from $\$ 3,380.6$ per ton in 2008 to $\$ 5,574.6$ per ton in 2017. Figure 6.5 shows the growing trend of the mentioned parameter. Figure 6.6 illustrates the 
percentage of purchasing cost changes for lambs based on Figure 6.5. According to Figure 6.6, the average of changes in the percentage of purchasing cost for cows is $6 \%$.

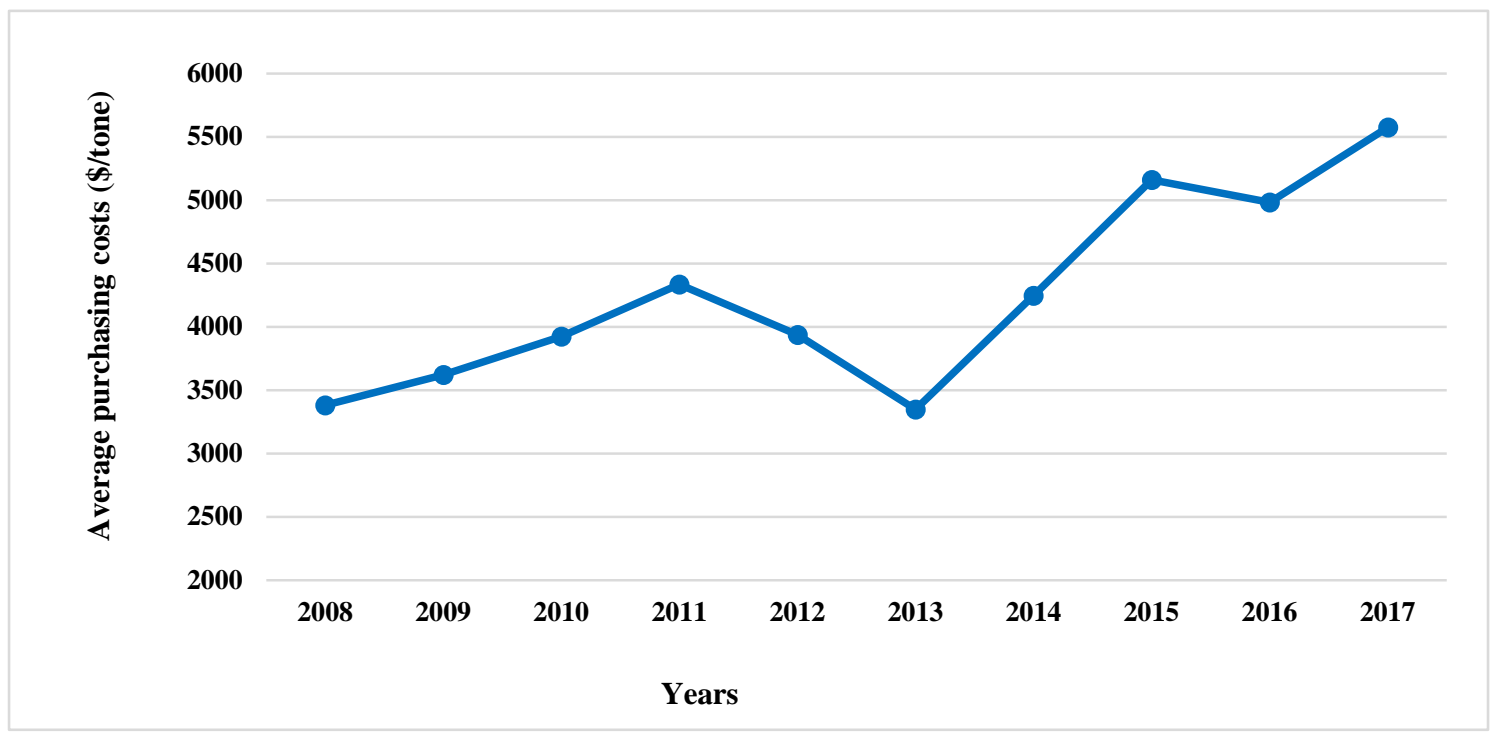

Figure 6. 5. Average purchasing cost of livestock from farmers by slaughters for Lamb (OMAFRA, 2018c)

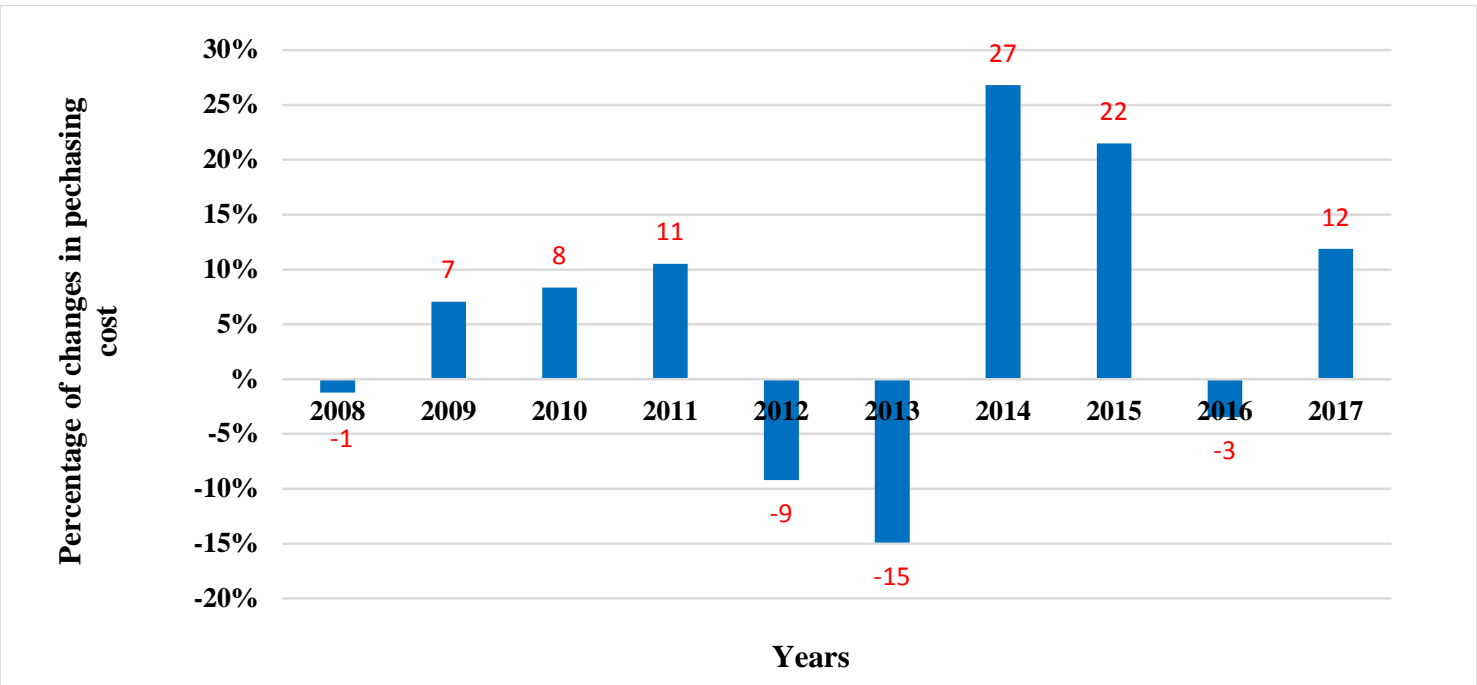

Figure 6. 6. Percentage of perchasing cost changes for Lambs (OMAFRA, 2018c) 


\subsubsection{Changes in demand and purchasing cost of livestock from farms}

In this subsection, the effects of changing the uncertain parameters are investigated on the single period model for the second product, lamb. Like the first product, it is assumed that the demand of Lamb increases or decreases by $20 \%$ with the probability of 0.5 . As it was explained in the previous subsection, the purchasing costs of livestock increase or decrease by $6 \%$ with the probability of 0.5 . The discount rate, $d r$, is remained the same, 0.1 for each year. Figure 6.7 shows the decision tree. Transition probabilities are defined for each arrow as $0.5 * 0.5=0.25$. Table 6.6 includes the calculated cost values for each node of Period 2. Like the first product, these results acquired through employing the augmented $\varepsilon$-constraint method for solving the single period multi-objective mixed-integer linear programming model for each node of Period 2 while $v=3$. Tables 6.7 and 6.8 contain the total cost in Period 1 and Period 0 , respectively. The PVTC in this case is equal to $13,449,896$, which is very close to the PVTC of the first product $(13,449,952)$. 


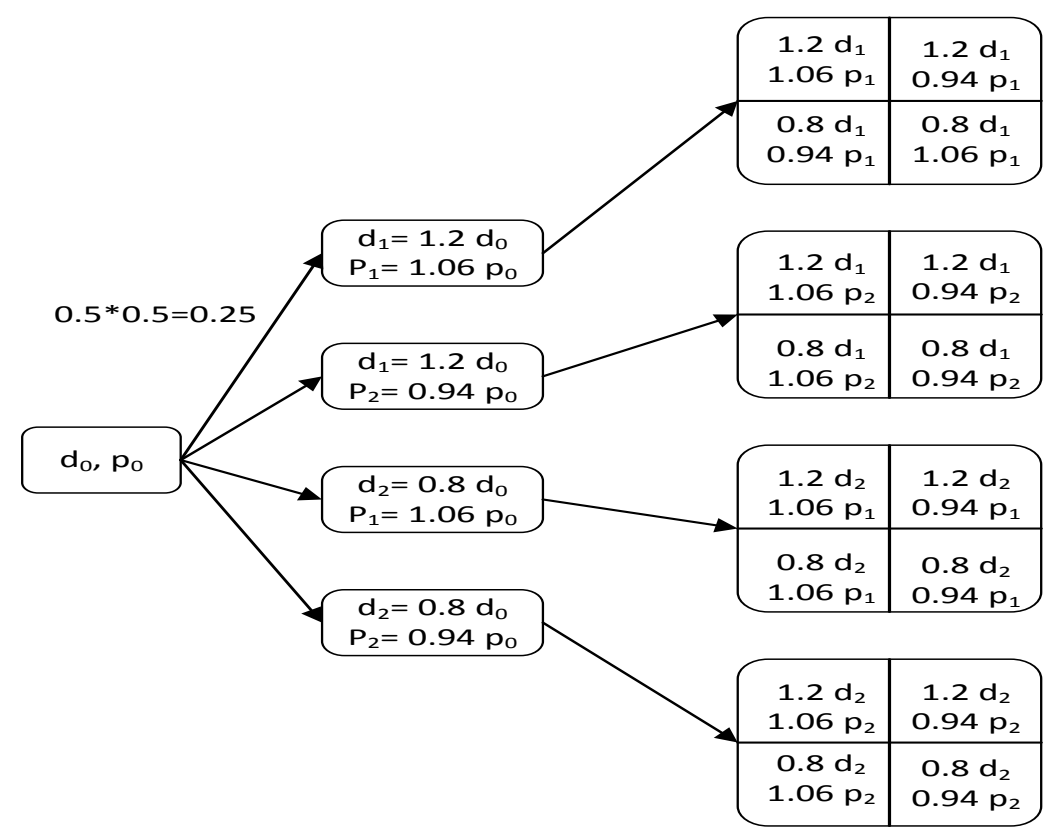

Figure 6. 7. Decision tree (second product)

Table 6. 6. Cost in Period $2(v=3)$

\begin{tabular}{cc}
\hline Node & Cost $(\$)$ \\
\hline $1.2 d_{1}, 1.06 p_{1}$ & $5,972,146$ \\
$1.2 d_{1}, 0.94 p_{1}$ & $5,918,419$ \\
$0.8 d_{1}, 0.94 p_{1}$ & $4,910,920$ \\
$0.8 d_{1}, 1.06 p_{1}$ & $4,946,735$ \\
$1.2 d_{1}, 1.06 p_{2}$ & $5,918,419$ \\
$0.8 d_{1}, 1.06 p_{2}$ & $4,910,920$ \\
$0.8 d_{1}, 0.94 p_{2}$ & $4,879,160$ \\
$1.2 d_{1}, 0.94 p_{2}$ & $5,870,774$ \\
$1.2 d_{2}, 1.06 p_{1}$ & $4,946,735$ \\
$1.2 d_{2}, 0.94 p_{1}$ & $4,910,920$ \\
$0.8 d_{2}, 1.06 p_{1}$ & $3,946,295$ \\
$0.8 d_{2}, 0.94 p_{1}$ & $3,922,421$ \\
$1.2 d_{2}, 1.06 p_{2}$ & $4,910,920$ \\
$1.2 d_{2}, 0.94 p_{2}$ & $4,879,160$
\end{tabular}




\begin{tabular}{ll}
$0.8 d_{2}, 1.06 p_{2}$ & $3,922,421$ \\
$0.8 d_{2}, 0.94 p_{2}$ & $3,901,249$ \\
\hline
\end{tabular}

Table 6. 7. Total cost in Period 1

\begin{tabular}{ccccc}
\hline Node & $\begin{array}{c}\boldsymbol{G}=\text { Expected cost in } \\
\text { Period 2 }\end{array}$ & $\begin{array}{c}\boldsymbol{K}=\text { Cost from Period 2 } \\
\text { in Period 1 = (G/1 + dr) }\end{array}$ & $\begin{array}{c}\boldsymbol{L}=\text { Cost of } \\
\text { Period 1 }\end{array}$ & $\begin{array}{c}\boldsymbol{K}+\boldsymbol{L}=\text { Total cost of } \\
\text { Period 1 }\end{array}$ \\
\hline $1.2 d_{0}, 1.06 p_{0}$ & $5,437,055$ & $4,942,777$ & $4,961,787$ & $9,904,564$ \\
$1.2 d_{0}, 0.94 p_{0}$ & $5,394,818$ & $4,904,380$ & $4,919,553$ & $9,823,933$ \\
$0.8 d_{0}, 1.06 p_{0}$ & $4,431,593$ & $4,028,721$ & $4,906,846$ & $8,935,567$ \\
$0.8 d_{0}, 0.94 p_{0}$ & $4,403,438$ & $4,003,125$ & $4,878,692$ & $8,881,817$ \\
\hline
\end{tabular}

Table 6. 8. Total cost in Period 0

\begin{tabular}{ccccc}
\hline Node & $\begin{array}{c}\boldsymbol{M}=\text { Expected cost in } \\
\text { Period } 1\end{array}$ & $\begin{array}{c}\boldsymbol{Q}=\text { Cost from Period } \mathbf{1} \text { in } \\
\text { Period 0 = (M/1 + } \boldsymbol{d})\end{array}$ & $\begin{array}{c}\boldsymbol{S}=\text { Cost of } \\
\text { Period 0 }\end{array}$ & $\begin{array}{c}\boldsymbol{Q}+\boldsymbol{S}=\text { Total cost of } \\
\text { Period 0 }\end{array}$ \\
\hline$d_{0}, p_{0}$ & $9,386,470$ & $8,533,155$ & $4,916,741$ & $13,449,896$ \\
\hline
\end{tabular}

\subsubsection{Changes in transition probabilities}

In this subsection, the probability of increase in uncertain parameters is changed from 0.5 to 0.6 while the probability of decline is changed from 0.5 to 0.4 . Figure 6.8 displays the decision tree. The new PVTC in this case is 13,629,095. Based on this calculation, changing one unit of transition probabilities can increase the PVTC by $1,791,989$ because $(13,629,095-$ $13,449,896) /(0.6-0.5)=1,791,989$. 


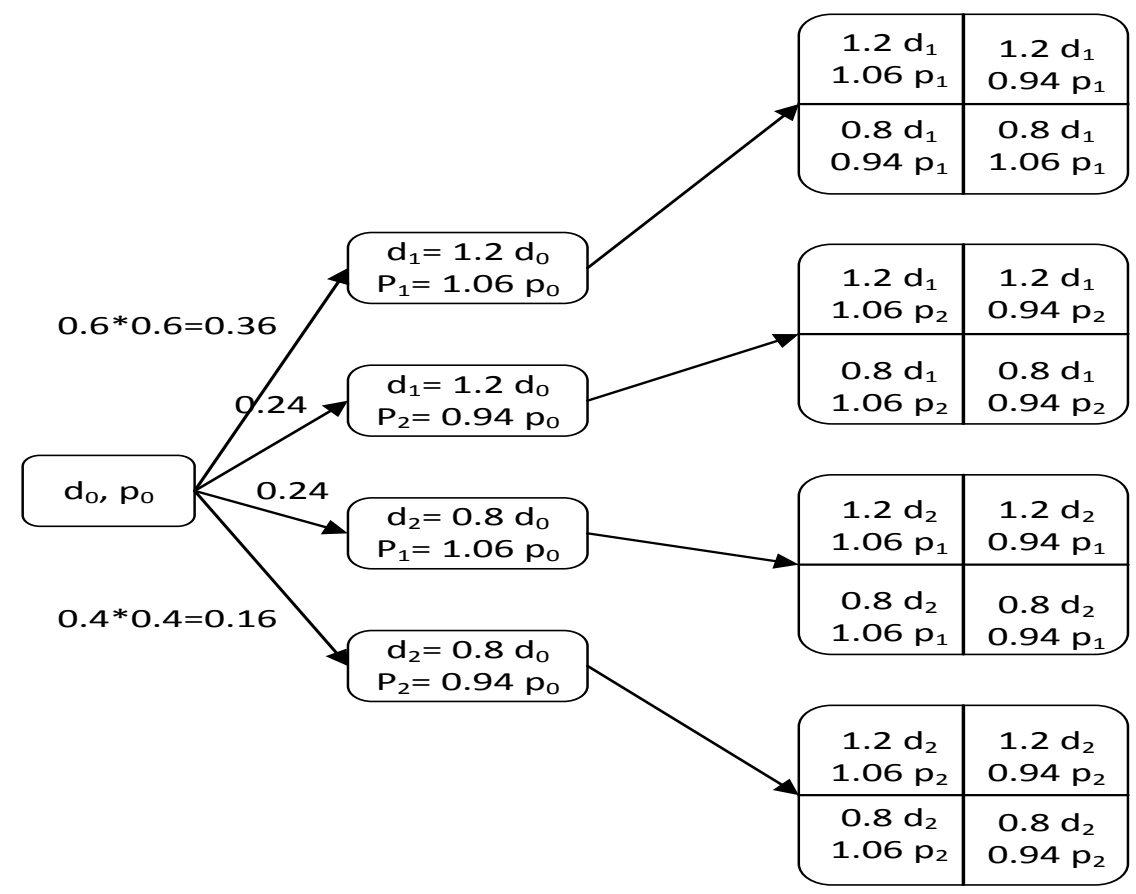

Figure 6. 8. Decision tree considering new transition probabilities

\subsubsection{Changes in rate of return}

In this subsection, the discount rate, $d r$, is changed from 0.1 to 0.15 . The rest of the parameters are remained the same. The new PVTC is 12,909,900, which shows that increasing the discount rate from 0.1 to 0.15 diminishes the PVTC by 539,999 because $(12,909,900-13,449,896) /(0.15$ $0.1)=-539,996$ 


\section{CHAPTER 7. CONCLUSIONS AND FUTURE RESEARCH}

\subsection{Research contributions}

The main research contributions of this research are as follows:

- Developing a novel multi-period, multi-product, multi-echelon, and multi-objective mixed- integer linear programming optimization model to design a meat supply chain network in Southern Ontario, Canada.

- Considering both economic and environmental goals in the proposed model.

- Considering a comprehensive supply chain network including final customers as the important part of a meat supply chain network.

- Taking into account real distances between real locations of the facilities of the network using Google Maps.

- Employing real data to analyze a green meat supply chain network in Ontario, Canada.

- Developing a solution approach based on augmented $\varepsilon$-constraint technique.

- Providing information for decision-makers to consider the trade-off between economic, environmental, and capacity objectives by generating Pareto-optimal solutions.

- Taking into account the effects of uncertainty in the proposed network based on several decision trees.

\subsection{Conclusions}

In this thesis, a multi-product, multi-period, and multi-objective mixed-integer linear programming model has been developed to design and optimize a multi-echelon supply chain network including multiple farms, abattoirs, retailers, and customers. Therefore, a 
comprehensive network in the meat industry, which includes different elements such as customers, has been considered in this research. The proposed mathematical model has integrated environmental objective with the economic objective to design a green supply chain network in the meat industry. Three important objectives have been optimized simultaneously in this research. They include minimizing total transportation costs and fixed costs, minimizing total $\mathrm{CO}_{2}$ emissions released from transportation, and maximizing total capacity utilization in each echelon of the network. The proposed model in this research is able to determine the optimum numbers of products that are transported in each echelon of the network, and the optimum numbers and allocations of farms, abattoirs, and retailers.

In the next step, the augmented $\varepsilon$-constraint method has been employed to solve the proposed model. Then, the model has been applied to design a green meat supply chain network in Southern Ontario, Canada, taking into account the real data including distances between different facilities of the network using Google Maps. A set of Pareto-optimal solutions, which gives a chance to decision-makers to make a trade-off between economic, environmental, and capacity objectives, and choose the preferred solution, has been obtained. Based on the above explanations, the first part of this research, which determines which facilities are open and how many products exist in each level of the network, is a facility location model.

In the second part of this research, the effects of uncertain parameters, which are customer's demand and purchasing costs of livestock from Ontario farmers, have been considered employing several decision trees. This method helps decision-makers to choose the best option of the network design by comparing the Present Value of Total Cost (PVTC). Finally, the impacts of changing some characteristics of the aforementioned method have been discussed and analyzed. To sum up, changing the uncertain parameters has approximately the same impact on 
the proposed model in both products. However, the obtained PVTC from the second product is slightly less than that from the first product, only \$56. In addition, changes in transition probabilities increased PVTC in both products as follows: $1.26 \%$ in the first product and 1.33\% in the second product. This means that costs will be increased if transition probabilities change in each product. Therefore, decision makers should keep them fix. Furthermore, increasing the discount rates decreased PVTC in both products by approximately 4\% because the return rate of money is increased.

\subsection{Future research}

Some future research directions for this work are as follows: considering inventory of meats in abattoirs and/or retailers; adding more objectives to the proposed model such as minimizing the delivery time of meat products that has direct impacts on the meat quality; employing the metaheuristics methods to solve large-sized problems; solving the model with other methods such as weighted sum and $\varepsilon$-constraint methods and comparing the results with those obtained in this study; developing the stochastic programming models and comparing the results with those obtained from decision tree method in this study. Furthermore, considering the impacts of uncertain parameters simultaneously on both products can be another research development for this study.

In Chapter 1, reverse supply chain and closed-loop supply chain have been introduced. It is valuable to consider food waste management and reverse supply chain, and develop and optimize the extended networks. 


\section{REFERENCES}

Abdallah, T., Farhat, A., Diabat, A., \& Kennedy, S. (2012). Green supply chains with carbon trading and environmental sourcing: Formulation and life cycle assessment. Applied Mathematical Modelling, 36(9), 4271-4285.

Agriculture and Agri-food Canada. (2017). Processed food and beverages sector, industry overview. Retrieved from:

http://www.agr.gc.ca/eng/industry-markets-and-trade/canadian-agri-food-sector-

intelligence/processed-food-and-beverages/?id=1361290991391, Accesses November 152018.

Ahmadi, A., Aghaei, J., Shayanfar, H. A., \& Rabiee, A. (2012). Mixed integer programming of multiobjective hydro-thermal self-scheduling. Applied Soft Computing, 12(8), 2137-2146.

Ahumada, O., \& Villalobos, J. R. (2009). Application of planning models in the agri-food supply chain: A review. European journal of Operational research, 196(1), 1-20.

Ahumada, O., \& Villalobos, J. R. (2011). A tactical model for planning the production and distribution of fresh produce. Annals of Operations Research, 190(1), 339-358.

Akkerman, R., Wang, Y., \& Grunow, M. (2009). MILP approaches to sustainable production and distribution of meal elements. In Computers and Industrial Engineering, 2009. CIE 2009. International Conference on (pp. 973-978). IEEE.

Akkerman, R., Farahani, P., \& Grunow, M. (2010). Quality, safety and sustainability in food distribution: a review of quantitative operations management approaches and challenges. Or Spectrum, 32(4), 863-904.

Amin, S. H., \& Zhang, G. (2012). An integrated model for closed-loop supply chain configuration and supplier selection: Multi-objective approach. Expert Systems with Applications, 39(8), 6782-6791

Amin, S. H., \& Zhang, G. (2013). A multi-objective facility location model for closed-loop supply chain network under uncertain demand and return. Applied Mathematical Modelling, 37(6), 4165-4176.

Amorim, P., Meyr, H., Almeder, C., \& Almada-Lobo, B. (2013). Managing perishability in production-distribution planning: a discussion and review. Flexible Services and Manufacturing Journal, 25(3), 389-413.

Aung, M. M., \& Chang, Y. S. (2014). Traceability in a food supply chain: Safety and quality perspectives. Food control, 39, 172-184.

Azadeh, A., Shafiee, F., Yazdanparast, R., Heydari, J., \& Fathabad, A. M. (2017). Evolutionary multi-objective optimization of environmental indicators of integrated crude oil supply chain under uncertainty. Journal of cleaner production, 152, 295-311. 
Babbar, C., \& Amin, S. H. (2018). A multi-objective mathematical model integrating environmental concerns for supplier selection and order allocation based on fuzzy QFD in beverages industry. Expert Systems with Applications, 92, 27-38.

Banasik, A., Kanellopoulos, A., Claassen, G. D. H., Bloemhof-Ruwaard, J. M., \& van der Vorst, J. G. (2017). Assessing alternative production options for eco-efficient food supply chains using multi-objective optimization. Annals of Operations Research, 250(2), 341-362.

Barter, H.C. (2014). Slaughterhouse Rules: Declining Abattoirs and the Politics of Food Safety Regulation in Ontario, A thesis submitted to the graduate department of university of Toronto

Bartholdi, J. J., \& Hackman, S. T. (2011). Warehouse and Distribution Science: Release 0.95, The Supply Chain and Logistics Institute, School of Industrial and Systems Engineering. Atlanta.

Bauer, J., Bektaş, T., \& Crainic, T. G. (2010). Minimizing greenhouse gas emissions in intermodal freight transport: an application to rail service design. Journal of the Operational Research Society, 61(3), 530-542.

Bektaş, T., \& Laporte, G. (2011). The pollution-routing problem. Transportation Research Part B: Methodological, 45(8), 1232-1250.

Bhattacharya, R., \& Bandyopadhyay, S. (2010). Solving conflicting bi-objective facility location problem by NSGA II evolutionary algorithm. The International Journal of Advanced Manufacturing Technology, 51(1-4), 397-414.

Bing, X., Bloemhof-Ruwaard, J. M., \& Van Der Vorst, J. G. (2014). Sustainable reverse logistics network design for household plastic waste. Flexible Services and Manufacturing Journal, 26(12), 119-142.

Bortolini, M., Faccio, M., Ferrari, E., Gamberi, M., \& Pilati, F. (2016). Fresh food sustainable distribution: cost, delivery time and carbon footprint three-objective optimization. Journal of Food Engineering, 174, 56-67.

Bosona, T., \& Gebresenbet, G. (2013). Food traceability as an integral part of logistics management in food and agricultural supply chain. Food control, 33(1), 32-48.

CFIA. (2018). Federally Registered Meat Establishments and their Licensed Operators. Retrieved from:

http://www.inspection.gc.ca/food/meat-and-poultry-products/registered-

establishments/eng/1374560511959/1374560512678, Accesses November 152018.

Chaabane, A., Ramudhin, A., \& Paquet, M. (2011). Designing supply chains with sustainability considerations. Production Planning \& Control, 22(8), 727-741.

Chaabane, A., Ramudhin, A., \& Paquet, M. (2012). Design of sustainable supply chains under the emission trading scheme. International Journal of Production Economics, 135(1), 37-49. 
Chankong V, Haimes Y. (1983). Multi-objective decision making theory and methodology. New York: Elsevier Science.

Chopra, S., \& Meindl, P. (2010). Supply chain management. Strategy, planning \& operation $\left(^{\text {th }}\right.$ ed). Pearson Prentice Hall Inc. ISBN 81-7758-003

Cheshmehgaz, H. R., Desa, M. I., \& Wibowo, A. (2013). A flexible three-level logistic network design considering cost and time criteria with a multi-objective evolutionary algorithm. Journal of Intelligent Manufacturing, 24(2), 277-293.

Chopra, S., \& Meindl, P. (2015). Supply chain management. Strategy, planning and operation ( $6^{\text {th }}$ ed.). New York: Pearson.

Coello, C. A. C, \& Romero, C. E. M. (2003). Evolutionary algorithms and multiple objective optimization. In Multiple criteria optimization: state of art annotated bibliographic surveys (pp. 277-331). Springer US.

Cooper, M. C., \& Ellram, L. M. (1993). Characteristics of supply chain management and the implications for purchasing and logistics strategy. The international journal of logistics management, 4(2), 13-24.

Cooper, M. C. (1993). International supply chain management: implications for the bottom line. Proceedings of the Society of Logistics Engineers, 57-60.

Cooper, M. C., Ellram, L. M., Gardner, J. T., \& Hanks, A. M. (1997). Meshing multiple alliances. journal of Business Logistics, 18(1), 67.

Dean, W. G. (1994). The Ontario Landscape, circa A.D. 1600. In Rogers, S.E. and D.B. Smith, (eds.), Aboriginal Ontario. Toronto: Dundurn Press Limited.

De Brito, M. P., \& Dekker, R. (2003). A framework for reverse logistics. Report Series Research in Management ERS-2003-045-LIS, Erasmus University Rotterdam.

Elhedhli, S., \& Merrick, R. (2012). Green supply chain network design to reduce carbon emissions. Transportation Research Part D: Transport and Environment, 17(5), 370-379.

Environment and Climate Change Canada. (2018). National inventory report 1990-2016greenhouse gas sources and sinks in Canada: Executive Summary

Felfel, H., Ayadi, O., \& Masmoudi, F. (2016). A decision-making approach for a multi-objective multisite supply network planning problem. International Journal of Computer Integrated Manufacturing, 29(7), 754-767.

Fleischmann, M., Krikke, H. R., Dekker, R., \& Flapper, S. D. P. (2000). A characterisation of logistics networks for product recovery. Omega, 28(6), 653-666. 
Fleischmann, M., Beullens, P., Bloemhof-Ruwaard, J. M., \& Van Wassenhove, L. N. (2001). The impact of product recovery on logistics network design. Production and operations management, 10(2), 156-173.

García-Flores, R., Higgins, A., Prestwidge, D., \& McFallan, S. (2014). Optimal location of spelling yards for the northern Australian beef supply chain. Computers and electronics in agriculture, 102, 134-145.

Gholamian, N., Mahdavi, I., Tavakkoli-Moghaddam, R., \& Mahdavi-Amiri, N. (2015). Comprehensive fuzzy multi-objective multi-product multi-site aggregate production planning decisions in a supply chain under uncertainty. Applied soft computing, 37, 585-607.

Govindan, K., Soleimani, H., \& Kannan, D. (2015). Reverse logistics and closed-loop supply chain: A comprehensive review to explore the future. European Journal of Operational Research, 240(3), 603-626.

Guillén, G., Mele, F. D., Bagajewicz, M. J., Espuna, A., \& Puigjaner, L. (2005). Multiobjective supply chain design under uncertainty. Chemical Engineering Science, 60(6), 1535-1553.

Güngör, A., \& Gupta, S. M. (2002). Disassembly line in product recovery. International Journal of Production Research, 40(11), 2569-2589.

Haines, R. (2004). The Meat Inspection Review. London, ON: Queen’s Printer for Ontario.

Harris, I., Naim, M., Palmer, A., Potter, A., \& Mumford, C. (2011). Assessing the impact of cost optimization based on infrastructure modelling on CO 2 emissions. International Journal of Production Economics, 131(1), 313-321.

Harris, I., Mumford, C. L., \& Naim, M. M. (2014). A hybrid multi-objective approach to capacitated facility location with flexible store allocation for green logistics modeling. Transportation Research Part E: Logistics and Transportation Review, 66, 1-22

Hassini, E., Surti, C., \& Searcy, C. (2012). A literature review and a case study of sustainable supply chains with a focus on metrics. International Journal of Production Economics, 140(1), 69-82.

House of Commons, Toward a common goal: Canada's food supply chain- Part 1. (2012). Report of the Standing Committee on Agriculture and Agri-food, 41st Parliament

James, S. J., James, C., \& Evans, J. A. (2006). Modelling of food transportation systems-a review. International Journal of Refrigeration, 29(6), 947-957.

Jindal, A., \& Sangwan, K. S. (2017). Multi-objective fuzzy mathematical modelling of closedloop supply chain considering economical and environmental factors. Annals of Operations Research, 257(1-2), 95-120. 
Kelly, K. (1971). Wheat Farming in Simcoe County in the Mid Nineteenth Century. The Canadian Geographer, 15, 95-112.

Keshavarz, M., Amiri, M., Olfat, L., \& Khatami Firouzabadi, S. A. (2017). Designing a multiproduct multi-period supply chain network with reverse logistics and multiple objectives under uncertainty. Technological and Economic Development of Economy, 23(3), 520-548.

Kheraj, S. (2013). Living and working with domestic animals in Nineteenth-Century Toronto. Urban Explorations: Environmental Histories of the Toronto Region, 120-140.

Kilcast, D., \& Subramaniam, P. (2000). The stability and shelf-life of food (pp. 1-22). Cambridge: CRC press.

Leng, M., \& Parlar, M. (2009). Lead-time reduction in a two-level supply chain: Noncooperative equilibria vs. coordination with a profit-sharing contract. International Journal of Production Economics, 118(2), 521-544.

Liang, T. F. (2006). Distribution planning decisions using interactive fuzzy multi-objective linear programming. Fuzzy Sets and Systems, 157(10), 1303-1316.

Lin, G. C., Kroll, D. E., \& Lin, C. J. (2006). Determining a common production cycle time for an economic lot scheduling problem with deteriorating items. European Journal of Operational Research, 173(2), 669-682.

Liu, S., \& Papageorgiou, L. G. (2013). Multiobjective optimisation of production, distribution and capacity planning of global supply chains in the process industry. Omega, 41(2), 369-382.

Mallidis, I., Dekker, R., \& Vlachos, D. (2012). The impact of greening on supply chain design and cost: a case for a developing region. Journal of Transport Geography, 22, 118-128.

Mavrotas, G. (2009). Effective implementation of the $\varepsilon$-constraint method in multi-objective mathematical programming problems. Applied Mathematics and Computation, 213(2), 455-465.

Mavrotas, G., \& Florios, K. (2013). An improved version of the augmented $\varepsilon$-constraint method (AUGMECON2) for finding the exact pareto set in multi-objective integer programming problems. Applied Mathematics and Computation, 219(18), 9652-9669.

McInnis, R. M. (1992). Perspectives on Ontario agriculture. Canadian Papers in Rural History, (VIII). Guelph, ON: University of Guelph, 1815-1930

Mirakhorli, A. (2014). Fuzzy multi-objective optimization for closed loop logistics network design in bread-producing industries. The International Journal of Advanced Manufacturing Technology, 70(1-4), 349-362.

Mirzapour Al-E-Hashem, S. M. J., Malekly, H., \& Aryanezhad, M. B. (2011). A multi-objective robust optimization model for multi-product multi-site aggregate production planning in a supply chain under uncertainty. International Journal of Production Economics, 134(1), 28-42. 
Mogale, D. G., Kumar, M., Kumar, S. K., \& Tiwari, M. K. (2018). Grain silo location-allocation problem with dwell time for optimization of food grain supply chain network. Transportation Research Part E: Logistics and Transportation Review, 111, 40-69.

Mohammed, A., \& Wang, Q. (2015). Integrity of an RFID-enabled HMSC network. In Proceedings of the Third International Conference on Digital Enterprise and Information Systems. China (pp. 79-86).

Mohammed, A., \& Wang, Q. (2016). An Investment Evaluation of a RFID-Enabled Meat Supply Chain: A Multi-Criteria Approach. In MATEC Web of Conferences (Vol. 70, p. 06003). EDP Sciences.

Mohammed, A., \& Wang, Q. (2017a). Developing a meat supply chain network design using a multi-objective possibilistic programming approach. British Food Journal, 119(3), 690-706.

Mohammed, A., \& Wang, Q. (2017b). Multi-criteria optimization for a cost-effective design of an RFID-based meat supply chain. British Food Journal, 119(3), 676-689.

Mohammed, A., \& Wang, Q. (2017c). The fuzzy multi-objective distribution planner for a green meat supply chain. International Journal of Production Economics, 184, 47-58.

Mohammed, A., Wang, Q., \& Li, X. (2017). A cost-effective decision-making algorithm for an RFID-enabled HMSC network design: A multi-objective approach. Industrial Management and Data Systems, 117(9), 1782-1799.

Moheb-Alizadeh, H., Rasouli, S. M., \& Tavakkoli-Moghaddam, R. (2011). The use of multicriteria data envelopment analysis (MCDEA) for location-allocation problems in a fuzzy environment. Expert Systems with Applications, 38(5), 5687-5695.

Moheb-Alizadeh, H., \& Handfield, R. (2017). An integrated chance-constrained stochastic model for efficient and sustainable supplier selection and order allocation. International Journal of Production Research, 1-27.

Moheb-Alizadeh, H., Mahmoudi, M., \& Bagheri, R. (2017). Supplier selection and order allocation using a stochastic multi-objective programming model and genetic algorithm. International Journal of Integrated Supply Management, 11(4), 291-315.

Mohebalizadeh, F., Amin, S. H., \& Zolfagharinia, H. (2018). Investigating a multi-objective problem for Ontario's meat supply chain network. Administrative Sciences Association of Canada Conference.

Mota, B., Gomes, M. I., Carvalho, A., \& Barbosa-Povoa, A. P. (2015). Towards supply chain sustainability: economic, environmental and social design and planning. Journal of Cleaner Production, 105, 14-27. 
Nair, S. D. M., \& Lau, K. H. (2012). Postharvest Food Wastage Reduction in Fruit and Vegetables through Cold Chain Collaboration: a Theoretical Framework. In VII International Postharvest Symposium 1012 (pp. 1311-1315).

Neto, J. Q. F., Bloemhof-Ruwaard, J. M., van Nunen, J. A., \& van Heck, E. (2008). Designing and evaluating sustainable logistics networks. International Journal of Production Economics, 111(2), 195-208.

Nurjanni, K. P., Carvalho, M. S., \& Costa, L. (2017). Green supply chain design: A mathematical modeling approach based on a multi-objective optimization model. International Journal of Production Economics, 183, 421-432.

OMAFRA. (2016). Introduction to organic farming. Fact sheet, ISSN 1198-712X. Retrieved from: http://www.omafra.gov.on.ca/english/crops/facts/09-077.htm, Accesses November 152018.

OMAFRA. (2017). Organic Meat Production in Ontario, Fact sheet, ISSN 1198-712X. Retrieved from:

http://www.omafra.gov.on.ca/english/livestock/beef/facts/09-067.htm, Accesses November 15 2018.

OMAFRA. (2018a). Provincial Abattoirs - Licensed Provincial Meat Plant Listing. Retrieved from: http://www.omafra.gov.on.ca/english/food/inspection/meatinsp/licenced_operators_list.htm, Accesses November 152018.

OMAFRA.(2018b). Livestock and Poultry Statistics. Retrieved from: http://omaf.gov.on.ca/english/stats/livestock/index.html, Accesses November 152018.

OMAFRA. (2018c). Average prices received by Ontario Livestock Farmers. Retrieved from http://www.omafra.gov.on.ca/english/stats/livestock/index.html, Accesses November 152018.

OMAFRA. (2018d). Food and Beverage - Sales Ontario and Canada. Retrieved from: http://www.omafra.gov.on.ca/english/stats/food/index.html, Accesses November 152018.

Oglethorpe, D. (2010). Optimising economic, environmental, and social objectives: a goalprogramming approach in the food sector. Environment and Planning A, 42(5), 1239-1254.

Olsen, P., \& Borit, M. (2013). How to define traceability. Trends in food science \& technology, 29(2), 142-150.

Özceylan, E., \& Paksoy, T. (2013). Fuzzy multi-objective linear programming approach for optimising a closed-loop supply chain network. International Journal of Production Research, 51(8), 2443-2461. 
Özceylan, E., \& Paksoy, T. (2014). Interactive fuzzy programming approaches to the strategic and tactical planning of a closed-loop supply chain under uncertainty. International Journal of Production Research, 52(8), 2363-2387.

Paksoy, T., Özceylan, E., \& Weber, G. W. (2010). A multi objective model for optimization of a green supply chain network. In AIP conference proceedings (Vol. 1239, No. 1, pp. 311-320). AIP.

Paksoy, T., Bektaş, T., \& Özceylan, E. (2011). Operational and environmental performance measures in a multi-product closed-loop supply chain. Transportation Research Part E: Logistics and Transportation Review, 47(4), 532-546.

Paksoy, T., Pehlivan, N. Y., \& Özceylan, E. (2012). Application of fuzzy optimization to a supply chain network design: a case study of an edible vegetable oils manufacturer. Applied Mathematical Modelling, 36(6), 2762-2776.

Pati, R. K., Vrat, P., \& Kumar, P. (2008). A goal programming model for paper recycling system. Omega, 36(3), 405-417.

Pishvaee, M. S., \& Razmi, J. (2012). Environmental supply chain network design using multiobjective fuzzy mathematical programming. Applied Mathematical Modelling, 36(8), 34333446.

Pourjavad, E., \& Mayorga, R. V. (2018). Optimization of a sustainable closed loop supply chain network design under uncertainty using multi-objective evolutionary algorithms. International Journal of Advanced Manufacturing Technology, 47(1-4), 269-281.

Rahimi, E., Paydar, M. M., Mahdavi, I., Jouzdani, J., \& Arabsheybani, A. (2018). A robust optimization model for multi-objective multi-period supply chain planning under uncertainty considering quantity discounts. Journal of Industrial and Production Engineering, 35(4), 214228.

Ramos, T. R. P., Gomes, M. I., \& Barbosa-Póvoa, A. P. (2014). Planning a sustainable reverse logistics system: Balancing costs with environmental and social concerns. Omega, 48, 60-74.

Rijpkema, W. A., Hendrix, E. M., Rossi, R., \& van der Vorst, J. G. (2016). Application of stochastic programming to reduce uncertainty in quality-based supply planning of slaughterhouses. Annals of Operations Research, 239(2), 613-624.

Rong, A., Akkerman, R., \& Grunow, M. (2011). An optimization approach for managing fresh food quality throughout the supply chain. International Journal of Production Economics, 131(1), 421-429.

Ruiz-Femenia, R., Guillén-Gosálbez, G., Jiménez, L., \& Caballero, J. A. (2013). Multi-objective optimization of environmentally conscious chemical supply chains under demand uncertainty. Chemical Engineering Science, 95, 1-11. 
Sabri, E. H., \& Beamon, B. M. (2000). A multi-objective approach to simultaneous strategic and operational planning in supply chain design. Omega, 28(5), 581-598.

Selim, H., Araz, C., \& Ozkarahan, I. (2008). Collaborative production-distribution planning in supply chain: a fuzzy goal programming approach. Transportation Research Part E: Logistics and Transportation Review, 44(3), 396-419.

Soto-Silva, W. E., Nadal-Roig, E., González-Araya, M. C., \& Pla-Aragones, L. M. (2016). Operational research models applied to the fresh fruit supply chain. European Journal of Operational Research, 251(2), 345-355.

Soysal, M., Bloemhof-Ruwaard, J. M., Meuwissen, M. P., \& van der Vorst, J. G. (2012). A review on quantitative models for sustainable food logistics management. International Journal on Food System Dynamics, 3(2), 136-155.

Soysal, M., Bloemhof-Ruwaard, J. M., \& Van der Vorst, J. G. A. J. (2014). Modelling food logistics networks with emission considerations: The case of an international beef supply chain. International Journal of Production Economics, 152, 57-70.

Statistics Canada. (2006). Ontario's Farm Population: Changes over a Lifetime. Retrieved from: http://www.statcan.gc.ca/ca-ra2006/agpop/on-eng.htm, Accesses November 152018.

Statistics Canada, Census of Agriculture. (2017). Statistical Summary of Ontario Agriculture, Farm Statistics, 2001, 2006, 2011 and 2016 Census. Retrieved from: http://www.omafra.gov.on.ca/english/stats/agriculture_summary.htm\#farm, Accesses November 152018.

Shukla, M., \& Jharkharia, S. (2013). Agri-fresh produce supply chain management: a state-ofthe-art literature review. International Journal of Operations \& Production Management, 33(2), 114-158.

Steven, M. (2004). Networks in reverse logistics. In Supply chain management and reverse logistics (pp. 163-180). Springer, Berlin, Heidelberg.

Talaei, M., Moghaddam, B. F., Pishvaee, M. S., Bozorgi-Amiri, A., \& Gholamnejad, S. (2016). A robust fuzzy optimization model for carbon-efficient closed-loop supply chain network design problem: a numerical illustration in electronics industry. Journal of Cleaner Production, 113, 662-673

Teimoury, E., Nedaei, H., Ansari, S., \& Sabbaghi, M. (2013). A multi-objective analysis for import quota policy making in a perishable fruit and vegetable supply chain: A system dynamics approach. Computers and Electronics in Agriculture, 93, 37-45.

Tonanont, A., Yimsiri, S., Jitpitaklert, W., \& Rogers, K. J. (2008). Performance evaluation in reverse logistics with data envelopment analysis. In IIE Annual Conference. Proceedings (p. 764). Institute of Industrial and Systems Engineers (IISE). 
Torabi, S. A., \& Hassini, E. (2008). An interactive possibilistic programming approach for multiple objective supply chain master planning. Fuzzy sets and systems, 159(2), 193-214.

Ubeda, S., Arcelus, F. J., \& Faulin, J. (2011). Green logistics at Eroski: A case study. International Journal of Production Economics, 131(1), 44-51.

Vahdani, B., Tavakkoli-Moghaddam, R., Modarres, M., \& Baboli, A. (2012). Reliable design of a forward/reverse logistics network under uncertainty: a robust-M/M/c queuing model. Transportation Research Part E: Logistics and Transportation Review, 48(6), 1152-1168

Validi, S., Bhattacharya, A., \& Byrne, P. J. (2014). A case analysis of a sustainable food supply chain distribution system-A multi-objective approach. International Journal of Production Economics, 152, 71-87.

Van Der Vorst, J. G., Tromp, S. O., \& Zee, D. J. V. D. (2009). Simulation modelling for food supply chain redesign; integrated decision making on product quality, sustainability and logistics. International Journal of Production Research, 47(23), 6611-6631.

Villegas, J. G., Palacios, F., \& Medaglia, A. L. (2006). Solution methods for the bi-objective (cost-coverage) unconstrained facility location problem with an illustrative example. Annals of Operations Research, 147(1), 109-141.

Wang, F., Lai, X., \& Shi, N. (2011). A multi-objective optimization for green supply chain network design. Decision Support Systems, 51(2), 262-269.

Yang, G. Q., Liu, Y. K., \& Yang, K. (2015). Multi-objective biogeography-based optimization for supply chain network design under uncertainty. Computers and Industrial Engineering, 85, 145-156.

Yu, J., Gan, M., Ni, S., \& Chen, D. (2018). Multi-objective models and real case study for dualchannel FAP supply chain network design with fuzzy information. Journal of Intelligent Manufacturing, 29(2), 389-403.

Zarandi, M. H. F., Sisakht, A. H., \& Davari, S. (2011). Design of a closed-loop supply chain (CLSC) model using an interactive fuzzy goal programming. The International Journal of Advanced Manufacturing Technology, 56(5-8), 809-821. 